
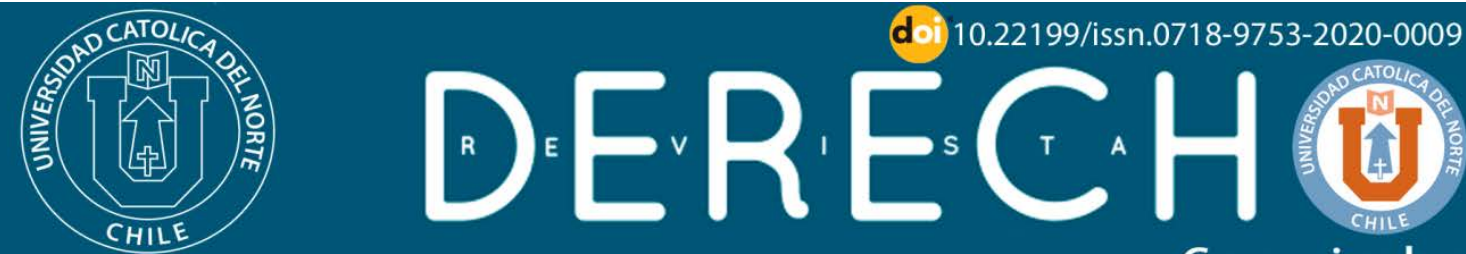

Co qu i m bo

REVISTAS CIENTIFICAS

ISSN: 0718-9753 (En línea)

\title{
Relaciones entre procedimiento administrativo y proceso jurisdiccional en el reclamo de ilegalidad municipal
}

\section{The relationships between the administrative procedure and the ju- risdictional process in the claim of municipal illegality}

\author{
Iván Hunter Ampuero' (D) https://orcid.org/0000-0002-0288-1812 \\ ${ }^{1}$ Universidad Austral de Chile, Valdivia, Chile. Profesor Derecho Procesal y Litigación Ambiental. Minis- \\ tro Titular Tercer Tribunal Ambiental de Valdivia. Doctor en Derecho, U. Carlos III, de Madrid, España

\section{Resumen:}

Se analizan las relaciones entre procedimiento administrativo y proceso jurisdiccional. Para ello se utiliza el reclamo de ilegalidad municipal como contencioso administrativo especial, sin perjuicio que sus conclusiones pueden extrapolarse a la gran mayoría de los contenciosos. Se analiza la siguiente pregunta: ¿En qué medida las posiciones jurídicas, pretensiones, prueba y alegaciones que el ciudadano realiza en sede administrativa, resultan obligatorias y vinculantes en la etapa judicial? La hipótesis que se esgrime, es que sí existen esas relaciones de congruencia que influyen en la interpretación y alcance de las normas procesales aplicables, especialmente en el ámbito de la prueba, los hechos y las normas jurídicas que resuelven la controversia.

Palabras Clave: Congruencia; Reclamo ilegalidad; Procedimiento administrativo; lura novit curia; Contencioso administrativo

\begin{abstract}
:
The relationships between the administrative procedure and the jurisdictional process are analyzed. To this end, the claim of municipal illegality as a special administrative litigation is used, without prejudice to the fact that its conclusions can be extrapolated to the great majority of the contenders. The following question is analyzed: To what extent are the legal positions, claims, evidence and allegations that the citizen makes in the administrative body and the mandatory and binding in the judicial stage? The hypothesis that establishes the relations of congruence that influence the interpretation and scope of the applicable procedural rules, especially in the field of evidence, facts and legal rules that resolve the controversy. Keywords: Congruence; Claim of municipal illegality; Administrative procedure; lura novit curia; Judicial review process
\end{abstract}


Relaciones entre procedimiento administrativo y proceso jurisdiccional...

\section{Introducción}

No cabe duda que uno de los principales centros de atención del Derecho Administrativo y Procesal, lo constituye el control judicial de la actividad de la Administración. Esta temática, ha jugado un rol clave en la consolidación de un Estado de Derecho. El denominado contencioso administrativo, ha permitido articular estándares y técnicas de control de la Administración que han mejorado sustancialmente la posición del administrado frente al poder del Estado. Sin embargo, todavía se siguen generando muchos problemas relacionados con el alcance de los poderes del juez y la interpretación de las normas procesales que lo disciplinan. La ausencia de una regulación general de los conflictos entre la Administración y los ciudadanos, así como la proliferación del recurso de protección como mecanismo desformalizado de control, pueden ser dos causas que explican los elevados niveles de incerteza que tienen las reglas procesales aplicables a estos procesos.

En Chile comienza una etapa importante en el estudio del contencioso administrativo. Superada la discusión de los modelos de justicia administrativa (Ferrada Bórquez, 2012 ; Bordalí Salamanca y Ferrada Bórquez, 2009, p. 233), la preocupación de la doctrina ha transitado desde el estudio de las instituciones generales del contencioso administrativo (Ferrada Bórquez y Sagredo Reyman, 2015) al tratamiento sistemático de contenciosos especiales (para el contencioso ambiental, vea; Méndez Ortíz, 2017; Bordalí Salamanca, y Hunter Ampuero, 2017). El avance ha sido importante. Sin embargo, esto contrasta con los estudios nacionales acerca del reclamo de ilegalidad municipal como contencioso administrativo especial. Aquí los esfuerzos doctrinales han sido más bien escasos, no obstante, puede observarse una increíble multiplicidad de problemas interpretativos y criterios jurisprudenciales (Hunter Ampuero, 2014; Lara Arroyo y García-Huidobro Herrera, 2015; Jequier Lehuede, 2013).

El presente trabajo, proyecta ser un aporte a la discusión del reclamo de ilegalidad municipal consagrado en el art. 151 de la Ley Orgánica Constitucional de Municipalidades (Decreto con Fuerza de Ley, $\left.N^{\circ} 1,2006\right)$. Esa pretensión tiene un sentido específico: analizar las relaciones, vinculaciones o conexiones entre procedimiento administrativo y proceso jurisdiccional. Se trata, en apretada síntesis, de responder la siguiente interrogante: ¿En qué medida las posiciones jurídicas, pretensiones, prueba y alegaciones que el ciudadano realiza en sede administrativa resultan obligatorias y vinculantes en la etapa judicial?

La pregunta en cuestión no se ha desarrollado en nuestro país, y se requiere una mirada interdisciplinaria desde el Derecho Procesal y Administrativo. En la medida que la jurisdicción puede revisar tanto el procedimiento administrativo, como el contenido sustantivo de la decisión (incluyendo la motivación del acto), la relación entre ambos no parece generar dudas. El problema es otro: cuál es el alcance y con- 
tenido de esas vinculaciones desde una perspectiva procesal. Esas relaciones, no son claras si nos preguntamos si las actuaciones y/o posiciones jurídicas que asumen los interesados o la Administración en el procedimiento administrativo que dio origen al acto que es el objeto de impugnación, tienen alguna consecuencia en el sentido y alcance de la interpretación de las reglas procesales.

La hipótesis que barajaré, es que sí existen relaciones entre el procedimiento administrativo y el proceso jurisdiccional que influyen en la interpretación y alcance de las normas procesales aplicables, relaciones que están determinadas primordialmente por el carácter revisor que tiene la jurisdicción contenciosa administrativa y por el objeto de la controversia, que en los procesos de revisión viene dada por la tensión entre satisfacción del interés general (la vigencia y legalidad de un acto administrativo) y la afectación del interés individual del impugnante (pretensión contenciosa administrativa). Esta hipótesis, requiere afirmar que el Derecho Procesal debe recoger aquellas herramientas que permitan la mejor forma de realización del derecho sustantivo (Derecho Administrativo), pero sin sacrificar los derechos fundamentales de orden procesal. Trataré de demostrar, que en el reclamo de ilegalidad municipal se exige una congruencia de las decisiones judiciales que no se vincula necesariamente a las posiciones jurídicas, decisiones y actividad de los interesados y la Administración en el procedimiento administrativo previo a la etapa jurisdiccional.

El camino que seguirá este trabajo es el siguiente: se entregarán algunos criterios para definir cómo se configura la omisión en la actividad administrativa municipal susceptible de ser sometida a control, y las relaciones entre procedimiento administrativo y proceso jurisdiccional. Me aprovecharé de la exigencia de agotar la vía administrativa previa, con la finalidad de determinar en qué sentido las cuestiones fácticas y jurídicas del reclamo interpuesto en sede jurisdiccional deben quedar necesariamente determinadas en la etapa administrativa. Posteriormente, se desarrollarán esas relaciones en tres ámbitos específicos: la aplicación de derecho, los hechos y la prueba. Para cada uno pretendo dar mi apreciación acerca de cómo los antecedentes y posiciones jurídicas asumidas por los impugnantes en sede administrativa, terminan siendo relevantes en sede judicial. Terminaré con las conclusiones.

\section{Configuración del acto u omisión ilegal y las relaciones entre pro- cedimiento administrativo y proceso judicial}

Comenzaré dando cuenta de las técnicas de control de la legalidad de un acto (vicios de anulabilidad), y luego, de las omisiones de la Administración. En esta última me interesa indagar con mayor profundidad, para efectos de definir exigencias de congruencias entre procedimiento administrativo y contencioso.

En líneas gruesas puede decirse que un acto es ilegal cuando su contenido se aparta del ordenamiento jurídico. El acto debe contrastarse con el derecho, sin que 
Relaciones entre procedimiento administrativo y proceso jurisdiccional...

pueda justificarse su impugnación en razones de mérito, oportunidad o conveniencia. La ilegalidad de un acto tiene un carácter complejo. Así, por una parte, puede considerarse que es ilegal aquel acto cuyos presupuestos fácticos de las normas que han servido a la Administración no se han efectivamente producido (Escribano CoIlado, 1993, pp. 364-365). La jurisprudencia ha conducido esta hipótesis a la falta de fundamentación del acto, estableciendo que, si los hechos que lo sustentan no se han producido, se infringe el deber de justificación que atañe a toda la actividad administrativa, así se dijo en fallo de la Corte Suprema, de 20 de abril de 2011, "...si la Administración basó una decisión discrecional -como lo es la contenida en el artículo 65 letra ñ) de la Ley $N^{\circ} 18.695$ - en determinados hechos que no fueron comprobados, la legalidad de aquella decisión se encuentra afectada por falta de fundamentación" (Ricardo Escobar Pérez contra Sr. Alcalde Municipalidad de San Joaquín, 2011, cons. 11)'. En rigor, el acto es ilegal no porque carezca de motivación, sino porque los supuestos materiales necesarios para el ejercicio de las potestades administrativas no se han verificado.

Las técnicas de control de legalidad se relacionan directamente con los motivos de ilegalidad. Siguiendo a Moderne (1993), es posible detectar diferentes tipos de control de legalidad: control de la legalidad externa, dentro de los que encontramos al control de la competencia del órgano o funcionario y del procedimiento. El control de la legalidad interna, donde se aprecia el control sobre el contenido del acto o violación de ley de fondo, de la motivación y el fin (desviación de poder) (Véase la tipología de Bermúdez Soto, 2014, pp. 162 y ss. y Moderne, 1993). Como es de esperar, la influencia francesa tuvo repercusiones en nuestra doctrina y jurisprudencia, pues la forma de configurar la ilegalidad del acto es muy similar en nuestro derecho: incompetencia del órgano, la falta de investidura regular de sus integrantes, los motivos del acto, y la sujeción a las formas preestablecidas por el legislador (Cordero Quinzacara, 2013, pp. 193-195). Cualquier infracción a estos aspectos podrá sustentar el reclamo de ilegalidad. En relación a los actos de trámite, esto es, aquellos que van preparando la decisión administrativa, se debe destacar que el reclamo de ilegalidad municipal no escapa a los estándares de control propios de los contenciosos administrativos, en el sentido que los vicios del procedimiento solo son impugnables separadamente cuando produzcan indefensión o pongan fin al procedimiento. Si esto no ocurre, deberán hacerse valer como fundamento o motivo de la impugnación del acto terminal (González Pérez, 1992, pp. 227 y 228; Bordalí Salamanca y Hunter Ampuero, 2017, pp. 327 y 328. En similar sentido, véase la sentencia, Empresa Nacional de Electricidad S.A. con Superintendencia del Medio Ambiente, 2016).

Respecto de las omisiones municipales el reclamo de ilegalidad también es procedente. Así lo dispone expresamente el DFL1 (2006, art. 151, a y b). No existe en nuestro derecho una regla general que permita la impugnación de la inactividad de 'También puede leerse en una sentencia de la Corte de Chillán, Sánchez Medina con Municipalidad de
Chillán (2011). 
la Administración, lo que no significa que esa inactividad no pueda ser llevada a los tribunales de justicia, como señala la doctrina

...el derecho constitucional a la tutela judicial efectiva exige que los Tribunales puedan reaccionar frente a la inactividad formal de la Administración que no ejerce sus potestades y que no dicta las correspondientes resoluciones que ponen fin al procedimiento (inactividad formal o declarativa). Cuando la pasividad se refiere al ejercicio de potestades cabe hablar de inactividad funcional (al no cumplirse las funciones públicas encomendadas a la Administración Pública para satisfacer el interés general)... (Blanquer Criado, 2007, p. 353)

Sin perjuicio de lo anterior, es necesario realizar una primera distinción para responder una pregunta más general acerca de si toda situación de pasividad administrativa puede ser objeto de impugnación o control jurisdiccional. Doctrinariamente es posible reconocer una inactividad formal y una inactividad material de la Administración.

La primera (inactividad formal), se refiere a los casos en que la Administración no ejerce sus potestades para la satisfacción del interés general; aquí la Administración abdica de su finalidad esencial que es promover el bien común, satisfaciendo de modo permanente y continua las necesidades públicas por medio de la dictación de actos administrativos. Este tipo de inactividad es llamada "inactividad funcional" (Blanquer Criado, 2007, p. 353), pues el aparato público no está cumpliendo su función y ha dejado de ejercer, en un caso concreto, sus potestades finalizadas².

La inactividad de la Administración también puede ser material, y consiste en la inejecución de actos firmes (Blanquer Criado, 2007, p. 353), esto es, hay pasividad en la ejecución de un acto administrativo que modifica el estatus quo generando una situación de ventaja, provecho o beneficio a un ciudadano o satisfaciendo directamente el interés público. La Administración no realiza una actuación material (fáctica) distinta a la pura dictación de un acto administrativo. También hay inactividad material, cuando la Administración deja de realizar una prestación al ciudadano estando obligado a hacerlo, casos en que si se añade un daño se incurre en falta de servicio (Cordero Vega, 2015, p. 628).

Ahora bien, no toda la inactividad de la Administración puede ser sometida a control con la misma intensidad. En este aspecto se ha dicho que

...el control judicial de la inactividad, por tanto, no abarca a todos los casos en que la Administración tiene el deber general de conducirse con diligencia y eficacia, sino únicamente cuando concurre una concreta y específica obligación, para la Administración, de actuar impuesta por una norma jurídica o

\footnotetext{
2 En el derecho español, la Ley 29 (1998, art. 29, 1) distingue entre la inactividad que se deriva de la pasividad en la realización de una prestación concreta, y la inactividad que corresponde a la inejecución coactiva del contenido obligacional de un acto administrativo (Ley 29, 1998, art. 29, 2).
} 
Relaciones entre procedimiento administrativo y proceso jurisdiccional...

derivada de una relación jurídica establecida. (Espín Templado et al., 2016, p. 181)

Similar opinión se sostiene en nuestra doctrina (Cordero Vega, 2015, p. 628).

Esta exigencia tiene pleno sentido para evitar que los tribunales de justicia condenen a la Administración a determinadas prestaciones que no están expresamente comprendidas en la programación normativa dispuesta por el legislador, respaldándose en normas que solo contemplan funciones y responsabilidades genéricas. Se trata de impedir que el juez en su sentencia influya en la programación administrativa de las políticas públicas, y en la asignación más eficiente de los recursos que realiza la Administración en sus espacios de discrecionalidad.

Por tal razón, para configurar la ilegalidad de la omisión no es suficiente la pasividad de la Administración. La ilegalidad del ente municipal no se produce con la simple inactividad. Es necesario que exista una obligación positiva imperativamente prevista por el ordenamiento o por un acto administrativo previo. Se ha dicho por la doctrina que:

Para evitar el riesgo de que el control de la inactividad se convierta en un cajón de sastre en el que buscar remedio ante cualquier comportamiento omisivo o puramente pasivo de la Administración, parece necesario subrayar que el control no es admisible ante cualquier tipo de inactividad, sino solamente cuando ésta supone un incumplimiento de sus deberes legales por parte de la Administración. Si no existe tal deber, no habrá incumplimiento, y por tanto, posibilidad de control. (Menéndez Rexach, 2001, p.169) ${ }^{3}$

Así se ha resuelto por nuestra jurisprudencia (véase Pedro Pablo Díaz Cordero y otros contra Alcalde de la I. Municipalidad de Chillán, 2010). Esto se da generalmente en los actos reglados, en que el ciudadano goza de un verdadero derecho subjetivo en contra de la Administración para exigir de ésta una prestación concreta (Cordero Vega, 2015, p. 628). La distinción entre deberes concretos y potestades discrecionales resulta relevante en el marco de la determinación de la ilegalidad de la omisión. Así, hay omisión ilegal cuando existe un deber concreto de actuación por parte de la Administración (derecho subjetivo del ciudadano), pero no cuando se está en presencia de una potestad de ejercicio discrecional (interés legítimo). En este sentido la tesis de Medina Alcoz (2005, pp. 297-298) parece muy interesante para explicar el derecho del ciudadano frente a la Administración las omisiones. Solo en el caso que el ciudadano es titular de un derecho prestacional -del "bien auspiciado" en palabras del autor-, se puede esperar una condena a la Administración para que satisfaga el bien en cuestión. En cambio, cuando el ciudadano detenta un interés legítimo, entonces solo tiene una expectativa de ventaja que no permite condenar a la Administración a dictar un acto en un determinado sentido o a realizar una prestación. Solo

\footnotetext{
${ }^{3}$ También: Valdivia Olivares (2017, p. 382). En este sentido, Vecinos Unidad Municipal de Providencia contra Municipalidad de Providencia (2017).
} 
cuando la omisión viola una posición de poder del ciudadano frente a la Administración, podrá exigirse la emanación de una prestación concreta.

Para configurar la omisión, no es suficiente que la Administración esté inactiva frente a una obligación concreta y específica que se encuentre prevista en una norma jurídica. Es además indispensable el requerimiento previo por parte del ciudadano a la Administración. Este requerimiento no está expresamente establecido, pero puede desprenderse de la parte final del DFL 1 (2006, art. 151, a y b) desde que el plazo de 30 días para interponer el reclamo, se computa "desde el requerimiento de las omisiones". No puede haber una omisión ilegal sin requerimiento del ciudadano al órgano administrativo ${ }^{4}$.

Se debe precisar que el requerimiento previo no tiene por objeto convertir la omisión de la Administración en un acto positivo de contenido negativo, aunque ciertamente puede generar ese efecto. El requerimiento previo permite individualizar la o las obligaciones que se estiman incumplidas por la Administración, así como también su fundamento fáctico y jurídico, por lo que se marca inevitablemente el contenido de la futura pretensión procesal (Huergo Lora, 2000, p. 230), siendo natural exigir una congruencia entre las prestaciones que se estiman omitidas y aquellas reclamadas. Con estos elementos, la Municipalidad puede discernir adecuadamente si su omisión es contraria a Derecho, y eventualmente adoptar las medidas necesarias para evitar la impugnación administrativa y contenciosa.

Con todo, en este caso la pretensión del ciudadano no será la anulación del acto administrativo (en rigor no hay acto previo) sino que la declaración de ilegalidad de la omisión de la Administración, unido a la condena a realizar una determinada prestación que puede consistir en dar, hacer o no hacer, a la que está obligada por la existencia de una relación jurídica sustancial que emana directamente de la ley (Cordón Moreno, 2001, p. 155). Así entonces, la Administración puede quedar obligada a realizar una prestación material como también a dictar un acto administrativo en un determinado sentido, como formas de restablecer plenamente la situación jurídica del administrado. Esto, sin embargo, y tal como se había indicado, cuando el ciudadano goza de una posición de poder frente al aparato público. Resulta interesante exponer aquí la tesis de Medina Alcoz (2016a, p. 273) en relación a la función que cumpliría el interés legítimo en el ámbito administrativo. Para el autor, el interés legítimo permite al ciudadano exigir el cumplimiento de la legalidad, abriendo espacios para el ejercicio de la discrecionalidad administrativa. Esta noción involucra, por un lado, la ausencia de un derecho subjetivo prestacional, pero sí la presencia de derechos subjetivos instrumentales derivadas de normas sustantivas o procedimentales.

\footnotetext{
${ }^{4}$ Así lo ha estimado la Corte Suprema en sentencia de 12 de junio de 2014 (Jaime Romero Donoso contra Señor Alcalde de la I. Municipalidad de Punta Arenas, Emilio Bocazzi Campos, 2014). De igual forma se lee en fallo de la Corte Suprema del 11 de mayo de 2009, "Gerardus Petrus van Eijck con llustre Municipalidad de Santiago". Así también la Corte de Apelaciones de Valparaíso en: Navieras Ultragas Limitada con Municipalidad de Valparaíso (2010).
} 
Relaciones entre procedimiento administrativo y proceso jurisdiccional...

En las omisiones esto se traduciría en la posibilidad de que el Municipio realice una prestación, pero no porque exista una previsión normativa que otorgue un derecho subjetivo a un ciudadano, sino por el ejercicio (adecuado) de la discrecionalidad.

\section{Relaciones entre la etapa administrativa y jurisdiccional: ¿hay una exigencia de congruencia o identidad entre ambas?}

El reclamo de ilegalidad municipal, atendido su doble naturaleza administrativa y jurisdiccional, constituye una buena fuente de reflexión acerca de la congruencia que resulta exigible entre procedimiento administrativo y proceso judicial. Este problema, ha sido objeto de arduas discusiones en el Derecho Comparado y recién comienza a ser tomado con seriedad en nuestro país. Quizás el caso más palmario que se ha resuelto, es la reclamación interpuesta por la Compañía Minera Maricunga con SMA, que resolvió el Segundo Tribunal Ambiental de Santiago, en sentencia de 31 de agosto de 2017, (Compañía Minera Maricunga con Superintendencia del Medio Ambiente, 2017). El reclamante, al momento de interponer el recurso de reposición ante la SMA, habría solicitado la adecuación de la sanción de clausura definitiva del sector pozos de extracción de agua ubicados en el corredor biológico PantanilloCiénega Redonda, pretensión que no se condice con la reclamación judicial en la que se había solicitado la anulación de la resolución sancionatoria en razón de que los cargos no eran claros ni precisos. De esta manera se advertiría una diferencia sustancial entre el objeto de la reclamación y la pretensión del recurso administrativo, lo que atentaría contra el carácter revisor que tendría la jurisdicción ambiental y lo desnaturalizaría (al que también más adelante señala como principio de congruencia). Señala a continuación que, si el sancionado decide agotar la vía administrativa y con posterioridad acudir a la jurisdicción e interponer el respectivo recurso contencioso administrativo, la revisión judicial debe versar sobre la misma pretensión hecha valer en sede administrativa, al tratarse de un verdadero juicio al acto. Se agrega que, dado que el reclamante no hizo valer en sede administrativa la falta de precisión y claridad en los cargos, ya sea al momento de formular sus descargos como en el ejercicio del recurso de reposición, no puede hacerlo al momento de interponer su reclamación judicial, pues aquello equivaldría a promover una cuestión nueva, que en el ámbito de la doctrina y jurisprudencia comparada, se denomina "desviación procesal". Otro caso en que también se manifiesta las relaciones entre procedimiento administrativo y proceso jurisdiccional lo constituye el resuelto por la Corte Suprema, en sentencia de 15 de enero de 2018, Rol N²58-2017, sobre impugnación del art. 3 letra h.i) del DS 40/2012, donde la Corte señaló: “...no existe congruencia entre el interés alegado en sede administrativa y aquel esgrimido ante el tribunal, discordancia que da cuenta de una falta de vinculación que contraría el principio conforme al cual la pretensión que el recurrente formule en vía jurisdiccional debe reproducir aquella hecha valer ante la Ad- 
ministración" (Herman Pacheco Patricio Edgardo y otros con Ministerio del Medio Ambiente, 2018).

La problemática resuelta constituye un aspecto ampliamente debatido en el Derecho Comparado, especialmente en el Derecho Español, que a partir de la Ley de Jurisdicción contencioso-administrativa de 1956 fue discutiendo acerca del carácter revisor de la jurisdicción contencioso administrativa (véase Fernández Torres, 1998, pp. 51 y ss.). En un primer momento, los debates se centraron en torno a si el pretendido carácter revisor de la jurisdicción permitía someter a los tribunales otro tipo de pretensiones que las meramente anulatorias, como las condenas a la Administración frente a las vías, la inactividad jurídica o material, etc. Posteriormente, y superada dicha problemática inicial, la disputa se centró en definir el rol del acto administrativo en la revisión jurisdiccional. Aquí aparecieron dos tesis: la primera (Blanquer Criado, 2007b, p. 58; García Pérez (1998a, p.49; Cordero Vega, 2009, p. 155), entendía que el acto administrativo previo era un requisito o presupuesto procesal que debía existir necesariamente para poder desarrollar un proceso. Sin el acto administrativo previo, no había posibilidades de revisión, y por ende, no se abría la vía jurisdiccional. En esta tesis, el impugnante no quedaba restringido en las declaraciones de hechos, derecho o las pruebas realizadas en sede administrativa, y podía plantear libremente su pretensión en sede jurisdiccional. La clave de esta tesis es muy simple: el objeto del contencioso es la pretensión, y el acto es solo un presupuesto procesal que no marca los límites ni el contenido del contencioso de revisión. La doctrina afirmó que "...el principio de inalterabilidad de la pretensión se formuló durante largo tiempo como la exigencia de que los tribunales se ciñesen a las cuestiones resueltas por el acto impugnado y a las pretensiones planteadas por las partes en la vía administrativa previa" (García Pérez, 1998b, p. 301). También no genera mayor discusión de que el impugnante puede reforzar la argumentación de su pretensión. En concreto, el ciudadano podría perfectamente, sin incurrir en desviación procesal, complementar y reforzar las argumentaciones jurídicas contenidas en el reclamo interpuesto en sede judicial.

La segunda tesis, más restrictiva, entendía que el acto administrativo materia de la revisión no solo constituía un presupuesto procesal, sino además marcaba los límites de las pretensiones, alegaciones y prueba que puede hacer valer el impugnante en sede judicial. La lógica que estaba detrás, es que la Administración debe tener la oportunidad de pronunciarse sobre todos los aspectos de la reclamación judicial, pues de lo contrario no habría propiamente una revisión si se pudiesen plantear pretensiones, argumentaciones o cuestiones nuevas en sede jurisdiccional. Lo anterior implicaría -resume esta tesis- una sustitución de la actividad administrativa previa.

Esta claridad cambia absolutamente cuando se trata de extremos más concretos: ¿Puede el ciudadano agregar hechos nuevos que no hayan sido materia del reclamo en sede administrativa o del procedimiento administrativo que da origen al 
acto impugnado? ¿Es posible que el tribunal considere vicios de ilegalidad del acto impugnado que no han sido invocados por el reclamante? La primera interrogante recibe una respuesta desde los elementos configuradores de la pretensión, y sobre todo, de la función del expediente administrativo como herramienta de control. La segunda, en cambio, puede responderse asumiendo una determinada posición de los poderes del juez en el contencioso administrativo, la función jurisdiccional y las garantías del procedimiento administrativo.

\section{1. ¿Es posible que el tribunal considere vicios o motivos de ilegalidad del acto impugnado que no han sido invocados por el reclamante?}

La interrogante planteada no ha sido abordada en plenitud en nuestro derecho, por más que en ocasiones se estime necesario intensificar los poderes del juez para la aplicación de las reglas jurídicas, en las controversias en la que subyacen intereses públicos o generales (Valdivia Olivares, 2015, p. 267) ${ }^{5}$. La pregunta acerca de si el juez de lo contencioso administrativo queda circunscrito a los vicios de ilegalidad que se alegan en la reclamación, o tiene plena libertad para estimar vicios de ilegalidad que no hayan sido invocados, requiere efectuar una serie de distinciones. Trataré de ensayar una respuesta que pueda considerar las particularidades de este contencioso especial, particularmente la necesidad de congruencia entre la etapa administrativa y judicial del reclamo.

En primer lugar, se debe tener presente que las cuestiones jurídicas del reclamo de ilegalidad deben quedar situadas en sede administrativa. En esta etapa se definen los aspectos jurídicos esenciales del reclamo, pues en rigor el reclamo de ilegalidad es uno solo, pero conocido en dos etapas sucesivas (En similar sentido; Bermúdez Soto, 2014, p. 565). De esta forma, el DFL1 (2006, art. 151, d), que exige al reclamante con precisión la norma legal que se supone infringida y la forma en que se ha producido la infracción, tiene un peso importante para definir el alcance de los poderes del juez.

Una primera lectura sugiere, entonces, considerar dos cuestiones: por una parte, el juez no puede atender vicios de ilegalidad que no hayan sido objeto de la reclamación, o que no se hayan formalizado mediante la afirmación clara y precisa de la infracción de una norma jurídica. La Corte Suprema en fallo de 2011 así lo dijo expresamente, más evidente fue la sentencia de la Corte Suprema, de 29 de junio de 2011, Rol No 9677-2009, que señaló que "...la competencia de la Corte de Apelaciones respectiva se encontraba circunscrita a las cuestiones propuestas por el reclamo de ilega-

\footnotetext{
${ }^{5}$ En el derecho español la Ley 29 (1998), dispone en el art. 33, 1, que los órganos del orden jurisdiccional juzgarán dentro del límite de las pretensiones formuladas por las partes y de los motivos que fundamenten el recurso y la oposición. Agrega en el art, 33, 2 que si el juez estimare que la cuestión sometida a su conocimiento pudiera no haber sido apreciada por las partes, por existir en apariencia otros motivos susceptibles de fundar el recurso o la oposición, lo someteré al escrutinio y debate entre las partes mediante resolución.
} 
lidad y su contestación, pero siempre en concordancia y conexión con los motivos del acto administrativo impugnado" (Emilio Fernando Dumont Bornandt contra Sr. Alcalde de la Municipalidad de Pitrufquén, 2011). Esta es la forma en que el proceso contencioso administrativo anuda su estructura dispositiva:

...el juez, no solo como es obvio, no puede dictar sentencia si no ha existido recurso, sino que también debe limitarse a examinar y controlar los presuntos vicios del acto que se han indicado en el recurso (de forma que la más flagrante ilegalidad no puede llevar a la anulación si no ha sido indicada por la parte), en relación exclusivamente a los actos que son recurridos, y tampoco puede dictar una medida que no haya sido solicitada. (Falcon, 1993, p. 227) ${ }^{6}$

Por otro lado, debería existir una identidad o congruencia entre el reclamo de ilegalidad interpuesto en sede administrativa y el que se interpone en sede jurisdiccional. Partiendo de la base de que el reclamo es uno solo, no cabe duda que deba existir una identidad entre ambas presentaciones del reclamante. Así parece además haberse resuelto por alguna sentencia, esta postura, derivado del carácter formalista que se le ha dado al reclamo, es la que sostiene la Corte de Apelaciones de Valparaíso, en sentencia de 18 de agosto de 2010, Sociedad de Inversión Pizarro Limitada con Ilustre Municipalidad de Valparaíso (2010, cons. 1, 3 y 4).

Sin embargo, esta conclusión requiere ser ampliamente matizada, pues en la etapa judicial del reclamo es posible reconocer tanto la posibilidad de ampliar las cuestiones jurídicas a instancia del impugnante, como también constatar el ejercicio de poderes de oficio de la Corte en la aplicación de los materiales jurídicos. Revisaré a continuación algunos de esos casos:

\subsubsection{Respuesta fundamentada del alcalde}

Cuando el alcalde da respuesta fundada al reclamo en la etapa administrativa, eventualmente pueden introducirse modificaciones en la etapa judicial, pues el derecho de defensa permite al reclamante hacerse cargo de la justificación, planteando nuevos u otros argumentos. Ahora bien, respecto de la vinculación que debe existir entre la acción jurisdiccional y el objeto del recurso administrativo, me parecen acertados los fundamentos de García Pérez (1998b):

...el recurso administrativo tiene por naturaleza un alcance completamente distinto al recurso jurisdiccional: aquél tiene por objeto 'revisar' una actuación administrativa para lograr su anulación o modificación. Pero 'en relación' con esa actuación o con lo que resuelva la Administración a propósito del recurso, el interesado puede entablar cualquiera de las pretensiones previstas en los artículos 30 y siguientes de la LCA, que van mucho más allá de

\footnotetext{
${ }^{6}$ En el derecho italiano existe la posibilidad de agregar motivos adicionales a los que estructuran la impugnación, siempre y cuando se refieran a actos o hechos que el recurrente no pudiera conocer.
} 
Relaciones entre procedimiento administrativo y proceso jurisdiccional...

la simple anulación o revisión deducida ante el órgano administrativo. ( $\mathrm{p}$. 304)

De la respuesta del alcalde puede sugerir nuevos argumentos, perspectivas o derechamente una nueva controversia.

\subsubsection{Invocación de normas jurídicas infringidas como carga procesal}

En segundo término, la exigencia de señalar con precisión la norma jurídica infringida y la forma en que se produjo la infracción, tiene por finalidad situar la controversia y debate en unos contornos más o menos determinados. Esta exigencia debe ser interpretada como una carga procesal (Hunter Ampuero, 2015a, p. 63) -en consecuencia, no como deber- y obedece a razones evidentemente prácticas. La revisión del acto administrativo, siempre requiere de un bloque de legalidad de referencia que permita definir el ámbito y alcance de la controversia. El juez no puede revisar el acto confrontándolo con toda la legalidad, pues sería un deber difícil de cumplir en la práctica. Esa controversia puede rebasar incluso hasta el mismo acto administrativo previo, es decir, en sede judicial pueden plantearse cuestiones jurídicas que no han sido decidas precisamente por la Administración.

Una de las primeras herramientas utilizadas para atemperar el carácter revisor de la jurisdicción contencioso-administrativa, fue la distinción entre "cuestión litigiosa y motivos" (García Pérez, 1998b, p. 302. Esta distinción, si bien parte de una base dogmática, como en la Ley 29 (1998, art. 54), puede extrapolarse como argumento general. Según esta doctrina

...una cosa es la pretensión, de la que forma parte de los hechos y la petición stricto sensu, y otra cosa es la argumentación jurídica o fundamentación de aquella. Así cobra sentido el precepto comentado: los motivos o fundamentos jurídicos pueden ser introducidos en el proceso por las partes en cualquier momento apto para realizar alegaciones sobre la cuestión debatida, e incluso pueden ser apreciados de oficio por el órgano judicial (iura novit curia) siempre que se garantice el ejercicio del derecho de defensa... (García Pérez, 1998b, p. 302)

De esta manera se separa teóricamente la cuestión litigiosa, que sirve para singularizar o individualizar lo que constituye el objeto del contencioso administrativo, y los "motivos" que constituyen los razonamientos que pueden hacer valer las partes en sus defensas o pretensiones. No es necesario que estos motivos nuevos hayan sido planteados en sede administrativa.

Luego, cobra relevancia en sede contenciosa administrativa la distinción entre fundamento jurídico y fundamentación. Por fundamento jurídico, debemos entender la adscripción que un litigante formula de unos hechos a unas determinadas normas jurídicas, que le permite obtener el efecto jurídico pretendido en la reclamación. Este ejercicio requiere que el impugnante seleccione unos hechos que justifican la peti- 
ción concreta, que en el caso concreto es la anulación del acto administrativo. Esos hechos no pueden ser sino los que configuren la ilicitud de la actuación administrativa, y constituyen causa de pedir, entendida:

...no en el sentido de establecer los motivos o argumentos jurídicos que lo apoyan, que no forman parte de la pretensión stricto sensu, sino los acontecimientos de la vida en que se apoya la pretensión, los acontecimientos 'de hecho' que la individualizan y la diferencia de cualquier otra, a modo de delimitación del trozo o parcela concreta de la realidad al que la pretensión se refiere. (García Pérez, 1998b, p. 300)

Cuando esta relación es perfecta, no se produce inconveniente alguno con la aplicación que pueda hacer el juez del Derecho, ya que los hechos alegados darán lugar a las infracciones normativas alegadas en el recurso.

Sin embargo, puede haber situaciones en que el actor plantea en su reclamación una multiplicidad de hechos, los que permiten lograr el efecto pretendido (la anulación de un acto o disposición), pero bajo normas jurídicas diversas e incluso incompatibles con aquellas que se han hecho valer en la reclamación. En este caso, el fundamento jurídico quedará delimitado por aquellos datos fácticos -solo aquellos-, que según el impugnante permiten conceder el efecto jurídico. Son los materiales jurídicos invocados los que determinan los hechos relevantes. El juez no podría, en principio, considerar otros hechos distintos como presupuesto de las normas aplicables.

Por otra parte, fundamentación jurídica consistiría en la invocación de las razones jurídicas que permiten justificar o sustentar esa adscripción de hechos a las normas jurídicas concretas (Véase, al respecto, Comanducci, 2001, pp. 121 y 122). Consiste en un proceso de argumentación, que se sustenta tanto en los hechos que constan en el expediente administrativo, como en la utilización de las herramientas vinculadas a la interpretación jurídica. La fundamentación jurídica tiene más bien una función dialéctica y persuasiva, en la medida que supone exponer las razones para apoyar una decisión eventualmente favorable del juez, y que el efecto jurídico pretendido se desprenda de los hechos y normas invocadas. En otras palabras, la fundamentación jurídica representa aquella indispensable justificación que requiere toda demanda o pretensión para ser acogida (Iturralde Sesma, 2004, p. 119), la jurisprudencia, para el contexto de la motivación de la sentencia, ha comprendido a cabalidad esta distinción (por ejemplo: Villablanca Muñoz Miguel Ángel con J. A. International S. A y Muñoz Luza Juan Andrés, 2011), la jurisprudencia española también ha sido clara indicando que para las adecuadas concordancia y congruencia entre las vías administrativa y procesal, lo decisivo son los hechos y la pretensión, no los fundamentos jurídicos de ella ('iura novit curia') (Sentencia Tribunal Supremo, 1987). No se trata de la simple cita de un artículo o norma legal, sino del razonamiento jurídico expresado en la demanda (Nieva Fenoll, 2006, p. 182). 
Relaciones entre procedimiento administrativo y proceso jurisdiccional...

En consecuencia, en el reclamo de ilegalidad municipal interpuesto ante la Corte de Apelaciones, el reclamante podría: invocar normas jurídicas que no hayan sido mencionadas en sede administrativa, siempre que formen parte del debate o cuestión controvertida planteada; plantear otra interpretación de las normas que se estiman infringidas; mejorar y complementar la argumentación de su reclamo; hacerse cargo de los argumentos sostenidos por el alcalde en su rechazo en caso que sea expreso, etc. Lo anterior, sin embargo, dentro de los estrictos límites de la congruencia ${ }^{7}$.

\subsubsection{Control de oficio de los vicios de orden público}

La otra arista que puede ser explorada como justificación a una ampliación de los poderes del juez es la existencia de los denominados "vicios de orden público", los que, en palabras de Fernández Rodríguez (1969), consisten en que

...determinadas cuestiones tienen, en opinión del juzgador, una gravedad y un relieve especiales que justifican la intervención del Juez, incluso de oficio o por propia iniciativa -excepcionando así el principio de la justicia rogada-, y su valoración y solución preferentes -excepcionando también el orden normal de los pronunciamientos de la sentencia- (p. 50)

La existencia de vicios de orden público daría lugar a dos consecuencias: la primera, es que estos son de decisión previa al fondo de la cuestión debatida, es decir, el tribunal debe resolver previamente sobre la existencia de estos vicios para luego pronunciarse respecto de la pretensión. En segundo lugar, atendida la importancia de estos vicios el juez puede controlarlos de oficio, sin necesidad de petición del impugnante. Se trata de vicios graves, importantes, y que afectan elementos del procedimiento o del acto administrativo que le hacen restar toda legitimidad.

Lo anterior, evidentemente, genera un problema interpretativo que consiste en definir cuáles son los vicios de orden público que autorizan al tribunal para actuar de oficio. Si bien esta noción es amplia y vaga, creo que es posible estructurar algunas aproximaciones positivas y negativas. En primer lugar, por vicios de orden público no puede entenderse la infracción o falta de cumplimiento de cualquier norma de derecho público. Esto acarrearía una ampliación desmesurada del concepto, dado que puede considerarse de orden público todo el sistema regulatorio de la actividad estatal. En segundo lugar, me parece que los vicios de orden público deben identificarse y corresponder a los denominados "vicios esenciales del procedimiento", es decir, aquellos que se refrieren a un requisito esencial del acto o procedimiento ad-

\footnotetext{
${ }^{7}$ La jurisprudencia ha tenido una posición bastante prudente en relación a la vinculación del órgano jurisdiccional a los planteamientos jurídicos esgrimidos por las partes. Por un lado, ha dicho que el tribunal no queda determinado por los planteamientos jurídicos que formulan los litigantes, y por el otro, indica que dicha conclusión no disminuye la exigencia conforme a la cual el derecho aplicable tiene que vincularse a las acciones y excepciones, alegaciones y defensas que han formulado en el pleito. La razón que se esgrime es la certeza y seguridad jurídica como supuestos del justo y racional procedimiento. Aguas Araucanía S. A. con Comisión de Evaluación Ambiental IX Región (2018).
} 
ministrativo y generen un perjuicio al interesado (Ley $\mathrm{N}^{\circ} 19.880,2003$, art. 13, inc. 2). Estamos en presencia de situaciones en que la Administración, en el procedimiento administrativo o en el acto terminal, ha infringido ciertos requisitos o trámites que se consideran indispensables para la formación de la voluntad administrativa, de manera que sin su cumplimiento el acto terminal carece de toda legitimidad.

Luego, habrá vicio esencial del procedimiento en todos los casos en que el legislador así expresamente lo señala, como en la Ley 19.300 (1994, art. 9 bis), que considera vicio esencial del procedimiento de calificación ambiental, su aprobación o rechazo en contravención al Informe Consolidado de Evaluación en los aspectos normados del proyecto. De igual forma, la jurisprudencia nacional ha ido identificando ciertos requisitos o trámites que los considera esenciales en el procedimiento administrativo, como la motivación de $\operatorname{los}_{\text {actos }}{ }^{8}$, la imparcialidad del órgano a cargo del procedimiento ${ }^{9}$, la ausencia de contradicción ${ }^{10}$, etc. En el derecho comparado, la audiencia del interesado en el procedimiento administrativo es considerado un principio consustancial en la formación de la decisión, que cumple una función integradora, informadora e interpretativa, similar a los principios generales del derecho. En la gran mayoría de los ordenamientos jurídicos europeos que sirven de referencia al nuestro, la omisión de la audiencia es sancionada con la invalidez del acto, siendo considerando un trámite esencial. (Véase: Tardío Pato, 2006, p. 121; Gallardo Castillo, 2006, pp. 238 a 240).

Atendido lo anterior, no es necesario que en contexto del procedimiento administrativo se haya promovido alguna cuestión relativa a la existencia de estos vicios, pues siempre podrían ser esgrimidos por el impugnante como motivo de su pretensión, como también ser considerados de oficio por el juez sin necesidad de alegación previa.

\footnotetext{
${ }_{8}^{8}$ Rosales Orellana Rosa Alicia con Superintendencia de Electricidad y Combustible (2016); Antileo con Municipalidad de Arica (2017); Marlene Carrasco Díaz con Gobernación Provincial del Tamarugal y Servicio de Gobierno Interior (2017); Delgado/Contraloría General de La República (2017); Roberto Rodríguez Vergara en favor de Víctor Manuel Rodríguez Maban contra SERBANC (2017); Hernández/Municipalidad de Fresia (2017); Corporación para el Desarrollo de la Región de los Ríos con Ministerio del Medio Ambiente (2017); Vilches/Municipalidad de Concón (2017); Pey Tumanoff Roxana contra Mario Fernández Baeza Vicepresidente de La República y Otro (2017); Carla Francisca Bon Fuenzalida con Municipalidad de Codegua (2016).

${ }^{9}$ Así lo ha resuelto la Corte Suprema en diferentes sentencias; Colegio Almondale Valle con Superintendencia de Educación(2016); Sociedad Escuela Especial Diferencial Renacer Limitada con Superintendencia de Educación (2016); Escuela de Trastornos de la Comunicación Yamanqui, Yuly Calpe Zúñiga EIRL con Superintendencia de Educación (2015); Instituto San Pablo Misionero c Superintendencia de Educación (2015)

${ }^{10}$ Pueden verse las siguientes sentencias de la Corte Suprema: Ángelo Solís Ruiz con Municipalidad de Pirque (2017); Rodríguez/Superintendencia de Pensiones (2017); Inmobiliaria Patagonia S.A., Inmobiliaria Parque Tres S.A. con Alcalde de la I. Municipalidad de Providencia (2017); Huenchun Pilchulman Ana Rosa con Corp. Nac. y Des. Indígena (CONADI) (2017); Valenzuela/Jorquera (Dirección Obras I. Municipalidad Villa Alemana) (2017).
} 
Relaciones entre procedimiento administrativo y proceso jurisdiccional...

\subsubsection{Posibilidad de controlar de oficio los presupuestos de la acción interpues-}

ta

El otro supuesto en que es posible reconocer un amplio poder de los jueces en la aplicación del derecho, es para determinar la procedencia de la acción interpuesta. Esto quiere decir que, aun cuando las partes no discutan acerca del cumplimiento de los requisitos o presupuestos de la pretensión, los tribunales deben actuar de oficio en relación a los mismos. El consenso que pueda existir acerca de la correcta aplicación de una norma jurídica al caso concreto, no exime el deber del órgano jurisdiccional de verificar su correspondencia con el ordenamiento jurídico. En este sentido ha resuelto nuestra Corte Suprema, que entiende, por ejemplo, que corresponde a los jueces, de oficio, definir si la pretensión fue interpuesta dentro de plazo, aun cuando no haya sido objeto de controversia, La Corte Suprema, en sentencia de 29 de mayo de 2017, señaló:

...los tribunales, para resolver el asunto sometido a su decisión, están facultados para revisar el derecho aplicable, siempre que ello se encuentre conforme y sea congruente con los presupuestos fácticos de la pretensión intentada, actividad que realizaron los jueces del fondo. En efecto, frente al principio de congruencia se erige otro principio: iura novit curia, en el sentido que el juez conoce y aplica el derecho, sin que ello afecte la causa de pedir. En esta dirección, el órgano jurisdiccional no queda circunscrito a los razonamientos jurídicos expresados por las partes, lo que es trascendente, toda vez que los sentenciadores deben determinar si se configuran los requisitos jurídicos de procedencia de la acción incoada - dentro de los cuales se encuentra, por cierto, su oportunidad - lo que en la especie se realizó y lleva en definitiva a desestimar el presente acápite de nulidad. (Comunidad Mapuche Sucesión Quiñimil Pirul y otros con Comisión Evaluación Ambiental VIII Región, 2017, inc. 7)

En estos supuestos también podrían incluirse la falta de legitimación activa procesal, carencia de legitimación pasiva, la falta de agotamiento de la vía administrativa previa, la incompetencia absoluta del tribunal, la falta de capacidad o representación del impugnante, etc. Se puede apreciar que estas cuestiones se refieren esencialmente a los presupuestos procesales, esto es, a una serie de requisitos que establece la ley procesal y que deben concurrir para la formación válida de la relación jurídica procesal, los que deben ser controlados de oficio de los jueces como emanación del principio de legalidad. En el reclamo de ilegalidad municipal, no existe una etapa previa en la cual resolver las cuestiones formales; por lo mismo, son resueltas con las de fondo en la sentencia definitiva. Lo relevante, sin embargo, es que éstas pueden ser apreciadas de oficio, debiendo, en consecuencia, aplicarse las normas jurídicas aun cuando éstas no hayan sido incorporadas o discutidas por los litigantes.

Especial atención tiene, en este aspecto, el control oficioso de la legitimación activa sustantiva o material, pues se trata de determinar si el sujeto que interpone la pretensión tiene o goza de alguna posición de ventaja que se ve perjudicada o agra- 
viada por el acto impugnado. Esta legitimación, al parecer de la doctrina, es el primer elemento que el juez debe considerar al examinar si concurren los requisitos de la acción (Romero Seguel, 2014, pp. 103-104), por lo que la sentencia que se dicte declarando la falta de legitimación tendrá un carácter material o sustantivo, que producirá todos los afectos de cosa jugada (Romero Seguel, 1998, p. 692).

\subsubsection{Posibilidad de controlar de oficio la naturaleza del acto impugnado}

No es muy diferente la situación cuando se trata de la naturaleza de los actos impugnados, los que también pueden ser apreciados de oficio por el tribunal. En el contencioso administrativo, existe un consenso importante en orden que únicamente los actos terminales pueden ser objeto de control judicial ${ }^{11}$. Por actos terminales o definitivos comprende aquellos que ponen fin al procedimiento, pronunciándose sobre todas las cuestiones planteadas en el procedimiento (Cordero Vega, 2015, p. 253). La razón que estriba esta interpretación, es la economía procedimental y la afectación a los derechos e intereses legítimos. No es razonable ni económica una judicialización excesiva del procedimiento administrativo, dado que éste busca llegar pronto a la emanación de una decisión que satisfaga el interés público. La tutela judicial efectiva solo tiene sentido respecto del acto final, que es el único que tiene la naturaleza y entidad de afectar derechos e intereses legítimos ${ }^{12}$. Solo el acto final es capaz de producir efectos fuera del procedimiento en que es dictado, y de generar una lesión actual o futura en un derecho o posición subjetiva de ventaja de un ciudadano. Ahora bien, en la impugnación del acto terminal deben concentrarse todos los motivos o vicios que pudieron ocurrir en el procedimiento administrativo (Concesiones Recoleta S. A. con I. Municipalidad de Recoleta, 2017) ${ }^{13}$.

\footnotetext{
${ }^{11}$ Es necesario advertir que tratándose de la impugnación de actos municipales se produce un fenómeno bastante discutible. La jurisprudencia ha ido relajando esta exigencia, al permitir que el reclamo tenga por objeto un acto trámite siempre y cuando éste contenga una decisión. Pueden verse las siguientes sentencias: Naviera Ultragas limitada contra Alcalde I. Municipalidad de Valparaíso (2012); Inmobiliaria Collfran 2000 Ltda. contra Ilustre Municipalidad de Viña del Mar (2010); Inversiones Los Castaños Limitada con Alcalde de la I. Municipalidad de La Florida (2010); Inversiones CONFE Limitada con I. Municipalidad de Viña del Mar (2010); Inversiones Juana de Arco Limitada con I. Municipalidad de Viña del Mar (2010); Bellavista de Inversiones Limitada con Ilustre Municipalidad de Valparaíso (2011); Inversiones Santa Julia S.A. con llustre Municipalidad de Valparaíso (2011); Sociedad Rentas Ardantza Limitada con Ilustre Municipalidad de Casablanca (2011); Inversiones AF Limitada con Alcalde de la llustre Municipalidad de Macul Sergio Puyol Carreño (2011); Inversiones e Inmobiliaria REVI Limitada con I. Municipalidad de Viña del Mar (2010). C. Santiago, 14 de octubre de 2008, Rol 3415-2007; TRANSAP S.A. con Alcalde de la Ilustre Municipalidad de Requinoa (2006); Inversiones Las Fresas LTDA. en contra de Municipalidad de lo Barnechea (2006), e; Inversiones Covadonga Ltda. contra Municipalidad de Vitacura (2005).

${ }^{12}$ Así se ha pronunciado la jurisprudencia nacional: Bellavista Oveja Tome SpA con Consejo de Monumentos Nacionales (2017); Sociedad Agrícola EI Tranque de Angostura Limitada con Superintendencia del Medio Ambiente (2017); Inmobiliaria Casa de Italia S.A./Consejo de Monumentos Nacionales (2017).

${ }^{13}$ En los autos Rol No 3682-2017, "Ecomaule S.A con Superintendencia del Medio Ambiente" la Corte Suprema en sentencia de 20 de diciembre de 2017, declaró inadmisible un recurso de casación interpuesto en contra de una sentencia del Segundo Tribunal Ambiental por entender que ésta no se dirigía a impugnar una sentencia definitiva.
}

Rev. derecho (Coquimbo, En línea) 2020, 27: e4376 
Relaciones entre procedimiento administrativo y proceso jurisdiccional...

Esto produce una natural consecuencia en el ámbito de la impugnación judicial: por un lado, se excluyen los actos de trámite como objeto de la impugnación, dado que solo ordena el procedimiento, y sus efectos no van más allá del procedimiento administrativo, salvo las hipótesis en que causan indefensión, caso en el cual pueden ser impugnados separadamente del acto terminal - Esta hipótesis puede ser discutible. La Corte Suprema, en sentencia de 14 de agosto de 2017, (Concesiones Recoleta S. A. con I. Municipalidad de Recoleta, 2017), aceptó que detrás de la exclusión de la impugnación de los actos trámite se encuentra la lógica de la Ley N¹9.880 (2003, art. 15). Sin embargo, con anterioridad, en sentencia de 20 de septiembre de 2016, (Empresa Nacional de Electricidad S.A. con Superintendencia del Medio Ambiente, 2016), a propósito del contencioso administrativo ambiental, señaló que los actos de trámite cuando causan indefensión pueden ser impugnados, pero como motivo o razón de la impugnación del acto terminal, y no separadamente-, y por el otro, los actos confirmatorios o reproductorios no podrían ser calificados de actos terminales, como tampoco los actos de ejecución, pues no contiene decisión alguna, y solo se limitan a ejecutar otros actos o a reproducir su contenido.

De esta manera, la Corte podrá rechazar ex officio el reclamo cuando la pretensión se dirige en contra de un acto que no tenga el carácter de terminal, siendo irrelevante que tal circunstancia haya sido debatida o controvertida en sede administrativa e incluso en el contexto del mismo reclamo en sede jurisdiccional.

\subsubsection{Contradicción previa como límite a la aplicación del Derecho}

El problema que puede suscitarse en algunos de los casos señalados se relaciona con la falta de contradicción previa del asunto, esto es, que existen determinados presupuestos de la pretensión que al ser controlados de oficio no han sido objeto de debate por los interesados. Este inconveniente, no sucede en los ordenamientos -como el español- donde la posibilidad de acoger el reclamo en base a fundamentos no invocados por el impugnante que el motivo nuevo haya sido previamente sometido a una contradicción.

En esto hay que ser cuidadosos, especialmente cuando interviene en el proceso judicial el beneficiario del acto impugnado. Este sujeto tiene derecho a un permanente conocimiento de las normas jurídicas que se consideren aplicables al litigio, como también a saber de las modificaciones que el juez pretenda introducir en la sentencia definitiva, y que se aparten de la controversia desarrollada en el proceso (Ezquiaga Ganuzas, 2000, p. 36). Cabe señalar, que este argumento se ha repetido con bastante frecuencia en la jurisprudencia de la Corte Suprema en relación al recurso de casación. En numerosos fallos, nuestro máximo tribunal estima que no corresponde formalizar un recurso invocando normas que no hayan sido objeto de la controversia, argumentando infracción al principio de bilateralidad de la audiencia: Vecinos Unidad Municipal de Providencia contra Municipalidad de Providencia (2017). 
Así también: Aguas Araucanía S.A. con Comisión de Evaluación Ambiental IX Región (2018). Sin embargo, también ha relajado la exigencia de contradicción en cuanto a la oportunidad en que debe ser promovida. En los autos Rol N 47.629-2016, en sentencia de 29 de mayo de 2017, (Comunidad Mapuche Sucesión Quiñimil Pirul y otros con Comisión Evaluación Ambiental VIII Región, 2017), estimó que la alegación de extemporaneidad efectuada por el tercero coadyuvante de manera previa a la vista de la causa, era suficiente garantía de contradicción.

Partiendo de la base que la función de los tribunales de justicia será siempre la de determinar si la pretensión se ajusta al ordenamiento jurídico más allá de los extremos en que se haya debatido por las partes, no es cuestionable entender que puede aplicar de oficio el Derecho para rechazar un reclamo de ilegalidad municipal. Así, la Corte podrá tener en consideración motivos diferentes a los señalados por el Municipio en su informe; podrá entender que el acto administrativo no es susceptible de ser impugnado; que no se ha agotado la vía administrativa previa o que la reclamación ha sido interpuesta fuera de plazo, etc. Ello puede generar un grado de indefensión procesal, pero que es natural en toda resolución judicial que resuelve una controversia con base a sus propios argumentos.

Por otro lado, también entiendo que en el contencioso administrativo no solo existe un interés privado del que recurre. Se trata de un proceso en que se cuestiona la satisfacción del interés público (Valdivia Olivares, 2017, p. 352), se enjuicia el actuar de la Administración y la sujeción a la legalidad como elemento legitimador de la actividad estatal. Por tal razón, cuando el acto administrativo desconoce elementos o requisitos esenciales que le restan toda su legitimidad, la Corte puede actuar de oficio, pues más allá de la tutela de un derecho o interés promovido a instancia de un particular, también se enjuicia la sujeción de la actividad administrativa a estándares mínimos de racionalidad.

Esto ha ocurrido, en algunas ocasiones, respecto de los casos en que la ley establece que ciertas normas son de aplicación imperativa, y en consecuencia, deben ser aplicadas de oficio por el tribunal, como fue el caso resuelto por la Corte Suprema, en sentencia de 6 de noviembre de 2017,

...no se observa de qué manera se habría verificado el vicio de ultra petita denunciado, desde que los falladores adoptaron la decisión censurada por el recurrente como consecuencia del ejercicio de facultades que les permiten, precisamente, obrar de oficio, motivo por el que el recurso en examen será desestimado también en esta parte. (Comité Pro defensa del Patrimonio Histórico Cultural de Viña del Mar contra Res N¹135-2015 del Comité de Ministros (Servicio de Evaluación Ambiental. Tercero Coadyuvante: Inmobiliaria Punta Piqueros S.A.), 2017, cons. 14) 
Relaciones entre procedimiento administrativo y proceso jurisdiccional...

En este caso, la ausencia de una contradicción no genera indefensión, pues el tribunal deberá siempre aplicar esas disposiciones más allá si ha existido contradicción.

\section{2. ¿Es posible que el tribunal considere hechos o pruebas diferentes a las que han dado origen al acto impugnado o a la etapa administrativa del reclamo?}

\subsubsection{El entramado fáctico en el reclamo de legalidad y su relación con el pro- cedimiento administrativo}

El problema de la identidad fáctica entre procedimiento administrativo y proceso jurisdiccional tampoco ha sido explorado por la doctrina nacional. La cuestión, se centra en determinar hasta qué punto resulta admisible que en el contencioso administrativo se introduzcan alegaciones de hecho no incorporadas en la etapa administrativa o que conste en el expediente administrativo, e incluso hasta qué punto es posible aceptar que el impugnante asuma una posición jurídica diferente a la sustentada en sede administrativa.

Según la doctrina, la introducción del expediente administrativo en el contencioso administrativo cumple tres funciones: i) permite la igualdad de armas; ii) es un medio de prueba; iii) habita al tribunal para introducir hechos incorporados en el expediente administrativo (Blanquer Criado, 2007b, pp. 245 y 246. Véase, además; Tolosa Tribiño, 2011 y Barrero Rodríguez, 2006, pp. 382 y ss.). Se trata, como se podrá apreciar, de una cuestión clave desde que en el expediente administrativo se concentrará la totalidad de los hechos y antecedentes probatorios que justifican y respaldan la decisión administrativa.

La cuestión fáctica, y la conexión entre procedimiento administrativo y jurisdiccional, puede explorarse a través de tres distinciones: la primera es aquella que separa los hechos primarios o principales -que identifican la causa de pedir- y que conforman el supuesto fáctico de la norma jurídica aplicable al caso, con los hechos secundarios, que solo sirven de argumento para determinar la existencia de un hecho primario (Taruffo, 2009, pp. 119-120). Estos últimos pueden ser libremente apreciados e incorporados por el tribunal, dado que no alteran ni modifican la causa de pedir. En este aspecto el tribunal puede considerar todos los hechos que emanan del expediente administrativo o de las pruebas producidas en el proceso y que tengan el carácter de secundarios, aun cuando no hayan sido previamente alegados por el impugnante. Como estos hechos no identifican la causa de pedir no existe limitación de ninguna naturaleza en su incorporación. Ni el procedimiento administrativo ni la impugnación marcan límites para introducir esta clase de hechos. Distinta es la situación de los hechos primarios o identificares de la causa de pedir. Estos configuran y 
delimitan una determinada pretensión, y es necesario que la afirmación de existencia se haya realizado en el procedimiento administrativo previo.

El segundo problema se relaciona con la posibilidad de incorporar hechos nuevos o de nueva noticia en la etapa judicial. En nuestro derecho, la introducción de los hechos nuevos o de nueva noticia se encuentran regulados en la Ley $\mathrm{N}^{\circ} 1.552$ (1902, arts. 321 y 322), que serían aplicables al reclamo de ilegalidad atendido el carácter supletorio del Libro II de la Ley $\mathrm{N}^{\circ} 1.552$ (1902, art. 3). Lamentablemente estas normas no han tenido mucha aplicación en la práctica judicial, aun cuando en el Derecho Comparado han colmado la preocupación de la doctrina, especialmente respecto de los límites en que resulta tolerable la alegación de hechos nuevos o de nueva noticia (véase, Picó i Junoy, 2006, p. 89). En efecto, bajo la rúbrica "ampliación de prueba" en realidad se esconde una ampliación de los enunciados de hecho que las partes han introducido en el periodo de discusión del proceso. Nuestra legislación regula la agregación de hechos nuevos, pero bajo el manto de la ampliación de la prueba. Esta ampliación de hechos es perfectamente posible en el reclamo de ilegalidad, siempre y cuando se trate de hechos que no modifiquen la causa de pedir, ya que ello implicaría una modificación del objeto del proceso, como tampoco que modifiquen los aspectos subjetivos del proceso (Castillejo Manzanares, 2006, pp. 75-76). Tampoco resulta pertinente que estos modifiquen el petitum de la pretensión, pues se produciría una transformación de la pretensión, la que queda definida en la respectiva reclamación (Castillejo Manzanares, 2006, p. 76). Se trata, por tanto, de hechos que vienen a complementar o a reforzar los alegados por las partes, pero que no pueden sustituir, agregar o modificar la causa de pedir.

En otra categoría habría que incorporar a los hechos de nueva noticia, esto es, aquellos que se verifican en el mundo con anterioridad a los actos de alegación e incluso con anterioridad al procedimiento administrativo, pero que son conocidos con posterioridad a la posibilidad de introducirlos en la controversia en sede judicial. Estos datos fácticos se pueden introducir al proceso, pero tampoco pueden alterar o modificar la causa de pedir ni la petición, pues significaría una modificación del objeto de la pretensión y de sus fundamentos fácticos, lo que en nuestra legislación resulta inadmisible.

Es claro que estas disposiciones vienen a morigerar los efectos de un régimen rígido de preclusiones en lo relativo a las alegaciones de hechos, con el objetivo de asegurar una verdadera justicia material que exige que las controversias sean resueltas, en lo posible, con absoluta conexión con la realidad (Garberí Llobregat y Buitrón Ramírez, 2004, p. 259; véase además; Picó i Junoy 2006, pp. 64-72). No admitir estos hechos cuando pueden ser fundamentales para la resolución del litigio sería sumamente injusto, de ahí que la preclusión no rija para los hechos nuevos (nova producta) o los de nueva noticia (nova reperta), Picó i Junoy (2006, pp. 64-72), la petición de ampliación de prueba se somete a las reglas generales de los incidentes, pero se for- 
Relaciones entre procedimiento administrativo y proceso jurisdiccional...

ma un cuaderno separado y sin suspender el término probatorio (Ley $\mathrm{N}^{\circ} 1.552,1902$, art. 322, inc. 2). Esto significa que efectuada la solicitud se debe dar traslado a la contraparte para que conteste dentro del tercero día. Acá podrá alegar que no se dan las condiciones para estar en presencia de un hecho nuevo o de nueva noticia, o bien, junto a ello puede alegar hechos que reúnan las condiciones antes señaladas, o que tengan relación con los que en dicha solicitud se mencionan (Ley $N^{\circ} 1.552,1902$, art. 322 , inc. 1). La posibilidad que la ley confiere a la contraparte para poder alegar hechos nuevos o de nueva noticia, busca mantener el carácter dialéctico del juicio y permite materializar el derecho de defensa, que se vería gravemente vulnerado de impedir alegar hechos que privan o destruyan el efecto de los alegados.

Ahora bien, si bien se ha señalado que no resulta posible la introducción de hechos nuevos que modifiquen o alteren la causa de pedir, y que en este aspecto debe existir una congruencia entre el procedimiento administrativo y el jurisdiccional, la jurisprudencia de la Corte Suprema no ha exigido una identificación absoluta entre los hechos alegados en sede administrativa y judicial, de manera que la reclamación puede efectuar un mayor desarrollo de los hechos, antecedentes o argumentos previamente incorporados en la instancia administrativa (José Horacio Cayún Quiroz con Servicio de Evaluación Ambiental, 2017). La distinción que hace la Corte es acertada y sumamente relevante desde que, por un lado, establece exigencias de congruencia entre los hechos alegados en la sede administrativa y en la judicial, y a su vez, permite que esa conexión se produzca dentro de unos márgenes más o menos amplios que respetan la causa de pedir, pero que dan paso a la introducción de antecedentes y argumentos no considerados en la etapa administrativa.

Por último, un antecedente relevante en esta materia es la posibilidad de incorporar en sede judicial un relato fáctico diferente al señalado en la etapa administrativa. Esto puede resultar interesante cuando se trata del ejercicio de poderes discrecionales por parte de la Administración. La discrecionalidad requiere que la Administración complete y concrete la norma que dirige su actuación mediante hechos específicos, de manera de adaptarse a la realidad en la cual se aplica. En esta tarea de concreción del espacio de creación normativa, pueden existir desajustes entre aquellos hechos que el ciudadano estima que constituye el ejercicio correcto de la potestad discrecional y los que la Administración define para concretar su espacio de creación. La selección de los hechos que realiza la Administración opera, en este contexto, como el criterio de relevancia de los intereses seleccionados para la concreción y complementación de la norma que confiere el poder discrecional (Medina Alcoz, 2016b, pp. 134 y ss.; Rodríguez de Santiago, 2016, pp. 57 y ss.). Se trata de espacios de decisión (ponderación de intereses) que el legislador ha radicado exclusivamente en la Administración, y que por tal motivo no puede ser sustituido por la jurisdicción. Por ende, aquí debería operar una total congruencia entre el procedimiento administrativo y el proceso jurisdiccional, desde que los hechos relevantes serán aquellos que seleccione la Administración para complementar y concretar el supuesto de he- 
cho inexistente o inacabado, y mediante los cuales realizar una ponderación de los intereses en juego.

\subsubsection{La prueba en el reclamo de legalidad y su relación con el procedimiento administrativo}

Al igual que en otras latitudes, la regulación de la actividad probatoria en el contencioso administrativo nacional -y particularmente en el reclamo de ilegalidad municipal- ha sido tradicionalmente parca, en ocasiones deficiente y por sobre todo incompleta. La opción legislativa fue remitirse a las normas de la jurisdicción civil, en vez de optar por una regulación específica, que recoja las peculiaridades del caso. Por eso, las dudas se instalan cada vez que se trata de interpretar estas reglas procesales en los contextos de los litigios administrativos.

Con todo, la respuesta a la pregunta puede tener una doble aproximación: la primera de naturaleza teórica, relacionado con el carácter revisor que se le adjudica al contencioso administrativo anulatorio. En general la doctrina parte de la base de que cualquier reflexión que quiera hacerse de la prueba debe arrancar del carácter revisor del contencioso administrativo, desde que será la vía o etapa administrativa el momento en que se habrán cuestionado, debatido y probado los hechos, mediante la incorporación y valoración de los diferentes medios de prueba (Cordón Moreno' 2010 , p. 290). En este sentido es la fase administrativa donde el ciudadano debe proponer y practicar toda la prueba que estime necesaria para establecer la verdad de los hechos (Barrero Rodríguez, 2006, p. 382 y ss.) ${ }^{14}$. Las pruebas que se producen en sede jurisdiccional tienen un carácter residual, solo limitado al control de la corrección o fiabilidad de las pruebas practicadas en el marco del procedimiento administrativo, como también para salvar vicios que se puedan producir por la omisión o denegación injustificada de prueba en sede administrativa (Hunter Ampuero, 2015b, p. 234; Cordón Moreno, 2010, p. 290).

Esta restricción puede tener una explicación. La jurisdicción cumple una función meramente revisora de una actividad previamente desarrollada por la Administración, por lo que la existencia de información o antecedentes adicionales que no han sido previamente valorados por la Administración no es coherente con este sistema (Hunter Ampuero, 2015b, p. 234). Se produciría, en este caso, una suerte de "sustitución" de la decisión administrativa por la vía probatoria, desde que los tribunales de justicia actuarían en relación a información que no ha sido considerada por la Administración.

La segunda aproximación a esta pregunta es netamente dogmática. El reclamo de ilegalidad municipal se somete a las normas del recurso de apelación, y DFL1 (2006, art. 151, f), contempla la posibilidad de abrir un término probatorio conforme

\footnotetext{
${ }^{14}$ Con mucha referencia jurisprudencial del derecho español. 
a las normas de los incidentes. Dada esta regulación, y la posibilidad de abrir un término de prueba, se puede afirmar que la actividad probatoria es plena, sin restricciones de ninguna naturaleza respecto de los medios de prueba admisibles.

Mi posición, sin embargo, busca hacer compatibles ambos extremos, y pasa por postular una redefinición del objeto de la prueba (Blanquer Criado, 2007, pp. 19 y ss) ${ }^{15}$. Resulta evidente que los hechos aceptados por la Administración o por el interesado en el procedimiento administrativo o en el acto administrativo, no pueden ser cuestionados en sede judicial. No participan del concepto "hecho controvertido", y no son objeto de prueba. De esto se deriva que la controversia probatoria en sede jurisdiccional siempre versará sobre alegaciones de hecho que no hayan sido aceptadas por la Administración, ya sea porque no fueron objeto de prueba o la aportada fue insuficiente. Por otro lado, tampoco puede existir discusión en torno a que la determinación de los hechos que hace la Administración puede ser objeto de control por los tribunales de justicia (véase, Valdivia Olivares, 2017, pp. 358-364). Esto tiene algunas repercusiones en materia probatoria.

La primera, es que el objeto de la prueba en sede jurisdiccional estará constituido por los hechos que hayan sido controvertidos en la respectiva reclamación judicial, la que constituye el marco referencial al momento de fijar la disputa fáctica y probatoria. Esto excluye a los hechos aceptados por la Administración o el interesado, existiendo, por tal motivo, una fuerte congruencia entre ambas etapas. Así entonces el objeto de prueba se reduce considerablemente, pues versará solo sobre un aspecto concreto de la pretensión anulatoria.

La segunda, es que si bien es posible afirmar que atendido el carácter contextual (Ferrer Beltrán 2007, pp. 40 y 45) de la prueba, cualquier modificación, adición o supresión de un elemento de juicio supone un nuevo contexto informativo en que se adopta la decisión, entiendo que sobre estas razones debe primar el ejercicio del derecho a la prueba como manifestación del derecho de defensa. En efecto, el derecho a probar constituye una emanación del derecho a la defensa jurídica, y en último término, es un componente esencial del justo y racional procedimiento (Constitución Política de República de Chile, 2005, art. 19, n³, inc.). El ciudadano que quiere obtener una respuesta estatal favorable a sus intereses queda sujeto a una serie de cargas, dentro de las cuales se encuentra la de probar el o los hechos que justifican los motivos de su impugnación. Para que los ciudadanos puedan satisfacer adecuadamente las cargas probatorias que se le asignan, el ordenamiento jurídico les reconoce un amplio derecho a probar, esto es, el derecho a utilizar todos los medios de pruebas útiles y pertinentes. El debido proceso en el orden de la justicia administrativa supone reconocer a todos los ciudadanos la posibilidad de aportar prueba (Bordalí Salamanca, 2005, p. 379; Tarullo, 2004, pp. 62 y 63).

\footnotetext{
${ }^{15}$ Con especial referencia al control sobre los hechos en el Derecho Comparado.
} 
Este derecho importa, en términos genéricos, la posibilidad de impulsar una actividad probatoria mediante la proposición de los medios de prueba (Picó i Junoy, 1996, pp. 18 y 19) e involucra en términos correlativos el deber de admitir toda la prueba pertinente y relevante (hipotéticamente idónea) para aportar elementos de juicio sobre los hechos que tienen ser probados (Ferrer Beltrán, 2003). Desde este punto de vista, hay un principio indiscutido de que deben ser admitidas todas las pruebas que sean potencialmente idóneas para aportar, directa o indirectamente, elementos de juicio acerca de los hechos que tienen que ser probados. Como observa Ferrer Beltrán (2007) "el primer filtro, de orden epistemológico, prescribe la admisión de toda prueba que aporte información relevante sobre los hechos que se juzgan" (p. 42). Este principio es muy relevante, dado que sirve de criterio de orientación para la prueba que debe ser admitida en el contencioso administrativo.

Por otro lado, este derecho a probar se ejerce con total prescindencia de la actividad probatoria desarrollada en sede administrativa, ya que el legislador no ha condicionado la admisibilidad de la prueba a su ofrecimiento o práctica previa en sede administrativa. En efecto, como todos derechos fundamentales, el derecho a probar no es absoluto; está sometido a una serie de limitaciones que derivan de la función misma de la prueba, o de algunas restricciones impuestas por el legislador (Montero Aroca, 2005, pp. 149-150) para la protección o tutela de otros derechos o bienes jurídicos. La existencia de límites al derecho a aportar medios de prueba es ampliamente aceptada en el orden constitucional comparado. Cuando estos límites miran a la prueba misma se conocen como límites intrínsecos (de naturaleza epistemológica), y cuando se refieren a condiciones o requisitos impuestos por el legislador se trata de límites externos (sobre la distinción; Picó i Junoy, 1996, p. 39). Si la denegación de un medio de prueba se produce en razón de algunas de estas causas, no hay lesión al derecho a la prueba como tampoco que se produce una situación de indefensión. En España, la cuestión acerca si la denegación de la prueba puede servir como motivo para anular la decisión administrativa, ha sido objeto de innumerables pronunciamientos jurisprudenciales. En general, se ha dicho que para poder anular la decisión por vulneración al derecho a probar es necesario que se justifique por el impugnante una situación de indefensión material, demostrando cómo la prueba injustamente denegada tiene el mérito de modificar la resolución final, véase: Gallardo Castillo (2006, pp. 229-233).

En el reclamo de ilegalidad municipal el legislador no ha establecido limitaciones a la prueba que se relacionen con algunas de estas razones o que se refieran al procedimiento o etapa administrativa, como sí lo ha hecho en otros sectores del ordenamiento, un ejemplo de restricciones probatorias en el ámbito jurisdiccional lo encontramos en la Ley $N^{\circ} 20.600$ (2012). El reclamante puede utilizar los medios de prueba que señala el art. 29 inc. $3^{\circ}$, disposición que hace aplicable las reglas del recurso de apelación civil contenidas en los artículos 186 a 230 de la Ley N 1.552 (1902). De estas disposiciones, la única que se refiere a las pruebas es el art. 207 (Ley 
$\left.\mathrm{N}^{\circ} 1.552,1902\right)$, que comienza indicando que, salvo excepciones como la del art. 348 (prueba documental), no se admitirá en segunda instancia prueba alguna. Se complementa esta disposición con el mismo art. 29 in. $3^{\circ}$ (Ley N²0.600, 2012), que consagra una regla de inadmisibilidad probatoria para la testifical y la confesional. En consecuencia, en las acciones de reclamación no es admisible ninguna clase de prueba, sin perjuicio que la remisión a las reglas de la apelación permite entender que ante el Tribunal Ambiental el reclamante puede hacer una amplia utilización de la prueba documental (Ley $N^{\circ} 1.552,1902$, art. 348). Es posible que el legislador cree incentivos a la producción de la prueba en sede administrativa con la finalidad de que se logre la mejor decisión posible, disminuyendo los márgenes de error en la determinación y apreciación de los hechos. Para ello, puede crear filtros que permitan al juez declarar inadmisible la prueba que no se haya aportado a la etapa administrativa. Un ejemplo de restricción probatoria en sede judicial que se deriva de la actitud del impugnante en sede administrativa, es el art. 132 inc $12^{\circ}$ del Código Tributario (1974), que declara inadmisibles aquellos antecedentes que, teniendo relación directa con las operaciones fiscalizadas, hayan sido solicitados determinada y específicamente por el Servicio al reclamante y que éste no obstante disponer de ellos, no haya acompañado en forma íntegra. Una disposición como ésta, sin embargo, carece de todo correlato en el ordenamiento nacional, y su aplicación analógica a los demás contenciosos, carece de todo respaldo justificativo.

Distinta es la situación respecto de la Administración, ya que aquí la respuesta debe ser matizada. La conexión entre el procedimiento administrativo y el proceso judicial presenta características especiales tratándose de la posibilidad de suplir en el contencioso prueba que, aun siendo indispensable para la decisión, no fue practicada en la instancia administrativa (Barrero Rodríguez, 2006, p. 391). Varias razones pueden justificar esta restricción. En primer lugar, la vía jurisdiccional no es una segunda instancia de la vía administrativa, por lo que la Administración no puede suplir la actividad probatoria que debió solventar la decisión terminal. En este sentido, existen determinadas potestades administrativas (como las sancionatorias) cuyo correcto ejercicio exige que la Administración pruebe en el procedimiento administrativo la verdad de todos los extremos que justifican la sanción impuesta al ciudadano (Carloni, 2011, p. 55; Moraga Klenner, 2010, pp. 213-215). Se dice que aquí se aplica íntegramente el principio de presunción de inocencia, por lo que la Administración para sancionar debe contar con prueba de cargo válida, contradictoria (Barrero Rodríguez, 2006, p. 211) y suficiente de la existencia del hecho infraccional y de la culpabilidad ${ }^{16}$. Idéntico razonamiento puede trasladarse a los procedimientos que culminan con actos de gravamen, donde se imponen cargas, deberes u obligaciones a los ciudadanos (Cordero Vega, 2015, p. 252).

\footnotetext{
${ }^{16}$ Así opinan, entre otros, Aguado I Cudolà (2001, p. 93); Manzano Salcedo (2013, p. 14); Gómez Tomillo y Sanz Rubiales (2013, pp. 833 y ss.); Barrero Rodríguez (2006, pp. 207 y ss.); Rebollo Puig, Izquierdo Carrasco, Alarcón Sotomayor y Bueno Armijo (2009, p. 657).
} 
En segundo lugar, la Ley $\mathrm{N}^{\circ} 19.880$ (2003, art. 34 y 35) es categórica en establecer el deber de la Administración de instruir el procedimiento administrativo y de realizar todos los actos necesarios para la determinación, conocimiento y comprobación de los datos en virtud de los cuales deba pronunciarse los actos. A lo anterior, se suma la posibilidad de requerir informes a otros órganos de la Administración, especialmente a los organismos técnicos (Ley $N^{\circ} 19.880,2003$, art. 37), cabe considerar además que toda la actividad de instrucción que realiza el órgano encargado del procedimiento administrativo se somete a las garantías de contradicción consagradas la Ley $\mathrm{N}^{\circ} 19.880$ (2003, arts. 10 y 17, f). Esto quiere decir que, frente a una prueba producida por la Administración, el interesado tiene la oportunidad de participar activamente en su producción y sobre todo de producir prueba en contrario. Esto remarca el carácter epistémico que tiene el procedimiento administrativo, desde que la desformalización y amplias potestades de los interesados la configuran como instancia ideal para la recopilación de información. De esta manera, permitir que la Administración pueda suplir la actividad probatoria que debió producir y constar en el expediente administrativo, implica validar una decisión que se dictó sin los antecedentes que la justifican, y que es, por ende, arbitraria. En tercer lugar, y en coherencia con lo anterior, si bien la doctrina tiende a reconocer que en los contenciosos administrativos se aplica el principio de igualdad de las partes, como bien señala Bermúdez Soto (2014, p. 533), esta característica no es algo tan obvio en el origen del control jurisdiccional del aparato público, pues la jurisdicción contenciosa administrativa nace en el seno de la propia Administración, y no era preciso hablar de una contienda entre partes. La doctrina más dura indica que el principio de igualdad se

...quiebra aparatosamente en los procesos administrativos o, en general, en los procesos en que es parte la Administración Pública (...) Es un hecho incuestionable que la Administración no aparece ante el Juez como una parte procesal en régimen de igualdad con el particular que ella se enfrenta. La Administración Pública ni ante el juez deja de ser sujeto privilegiado, que goza de una serie de prerrogativas de hecho, en pugna abierta con la justicia. (González Pérez, 1992, p. 154)

Los privilegios procesales de la Administración han suscitado en nuestro país una ardua discusión, la que se centra en la constitucionalidad de las normas que establecen prerrogativas exorbitantes en el contexto del proceso judicial. Estas normas ya no se presentan en forma ostensible, pero ciertamente asumen ciertas modalidades, siendo la más patente los denominados "privilegios probatorios de la Administración" (Romero Seguel, 2016). Se trata de una afirmación controvertida, y de un problema que apenas podemos insinuar en este trabajo.

No es menos cierto, que estas restricciones a la prueba tienen una justificación desde el principio de legalidad que debe observar y actuar la Administración (Constitución Política de la República de Chile, arts. 6 y 7 y Decreto con Fuerza de Ley 1-19.653, 2001, art. 2). No obstante, hay fallos que exigen conexión (congruencia) e 
Relaciones entre procedimiento administrativo y proceso jurisdiccional...

incluso identidad entre los antecedentes que se ponderan en sede administrativa y los que el tribunal debe revisar (Cencosud Administradora de Procesos S.A. con Inspección Provincial del Trabajo Puerto Montt, 2014).

No obstante, no se debe olvidar que la Administración -en este caso la Municipalidad-, defiende y enarbola un interés público que entiende satisfacer con su actividad unilateral. La presunción, legalidad y ejecutividad de los actos de la Administración, obedece precisamente a dicha finalidad: materializar en el orden temporal una decisión jurídica para satisfacer una determinada necesidad pública. Por ende, la nulidad del acto administrativo derivado de la ausencia de un material probatorio que debió producirse en la etapa administrativa posterga, definitiva o temporalmente, la satisfacción de esa necesidad pública. Atendido el interés público concreto que se quiere satisfacer con el acto impugnado (como por ejemplo la protección de la vida o salud de las personas), las consecuencias de su anulación pueden ser irreparables. Por ende, en estos casos excepcionales, podría aceptarse la producción de prueba adicional en sede jurisdiccional destinada a justificar el acto impugnado, aplicando el principio de conservación del acto (Gallardo Castillo, 2006, pp. 229-233). Este principio, ha sido ampliamente aceptado por nuestra jurisprudencia, y no vislumbro ningún reparo para que en estas situaciones excepcionales pueda ser utilizado.

Lo anterior, no quita la posibilidad de que la Administración pueda realizar una actividad probatoria destinada a desvirtuar los hechos introducidos por el impugnante en su demanda, o para calibrar de mejor forma la prueba existente en el expediente administrativo.

Consecuencia de lo anterior, es que la prueba en sede jurisdiccional del reclamo de ilegalidad podrá comprobar o refutar una determina hipótesis de hecho que sirve de sustento a la pretensión; complementar la información proporcionada ante la Administración; aclarar la información oscura o dudosa que resulte del procedimiento administrativo; dar fiabilidad a la información aportada en sede administrativa aumentando su grado de confianza y respaldo a una hipótesis de hecho; y por último, acreditar los datos fácticos que permiten sustentar la legitimación como el perjuicio, la afectación, etc.(Hunter Ampuero, 2015b, p. 234)' por eso la doctrina ha señalado que "la aportación de nuevas pruebas y documentos no incorporados en la vía administrativa previa, no violenta la naturaleza revisora que caracteriza el orden jurisdiccional". Cordón Moreno (2010, p. 290). 


\section{Conclusiones}

1. En nuestro país se han superado las viejas discusiones en torno a los modelos de justicia administrativa para centrar la atención en las instituciones específicas del contencioso administrativo, y muy incipientemente en algunos contenciosos administrativos especiales.

2. En el análisis de los contenciosos administrativos especiales, la doctrina ha omitido hacerse cargo del problema acerca de las relaciones entre el procedimiento administrativo y el proceso jurisdiccional en que se revisa la legalidad del acto impugnado; y más específicamente, de la vinculación entre los hechos, la prueba y el derecho alegado en sede administrativa y la judicial. La respuesta a este problema supone interpretar y definir una serie de factores propios del Derecho Administrativo y Procesal.

3. Desde el punto de vista de las omisiones imputables al alcalde o sus funcionarios, es necesario que exista una obligación específica impuesta por una norma o un acto administrativo para que se configure su ilegalidad, unido además al requerimiento del ciudadano. De esta forma, en el requerimiento previo realizado en sede administrativa quedará definido el ámbito normativo que se estima infringido por la Administración, debiendo, en consecuencia, ser el mismo que sustenta el reclamo de ilegalidad en la etapa judicial. Existen aquí, por lo tanto, relaciones de congruencia entre procedimiento administrativo y judicial.

4. En el Derecho Comparado, las relaciones entre procedimiento administrativo y judicial fueron abordadas a través de la institución de la desviación procesal, la que a su vez sustentaría dos posiciones. La primera, entendía que el acto administrativo previo era un requisito o presupuesto procesal que debía existir necesariamente para poder desarrollar un proceso. En esta tesis, el impugnante no quedaba restringido en las declaraciones de hechos, derecho o las pruebas realizadas en sede administrativa, y podía, en consecuencia, plantear libremente su pretensión en sede jurisdiccional. La segunda tesis, más restrictiva, entendía que el acto administrativo materia de la revisión no solo constituía un presupuesto procesal, sino además marcaba los límites de las pretensiones, alegaciones y prueba que puede hacer valer el impugnante en sede judicial.

5. En cuanto a la posibilidad de utilizar en la etapa judicial libremente los materiales jurídicos, se estima que, por regla general, y atendido lo dispuesto en el DFL 1 (art. 151, d), los parámetros de la disputa jurídica deben quedar situados en sede administrativa. Sin perjuicio de ello, nada impide que el impugnante pueda innovar respecto de la fundamentación jurídica de la impugnación, pueda argumentar en relación a la respuesta dada por el alcalde. De igual forma, el tribunal (Corte de Apelaciones) debe ejercer un control de oficio de ciertos aspectos de la reclamación, por más que aquellos no hayan sido 
materia de la controversia en sede administrativa; tales son el control de los presupuestos procesales, la naturaleza del acto impugnado (verificar si es susceptible de ser impugnado) y la determinación de si existen vicios de orden público.

6. El problema que puede suscitarse en algunos de los casos se relaciona con la falta de contradicción previa del asunto, esto es, que existen determinados presupuestos de la pretensión que al ser controlados de oficio no han sido objeto de debate por los interesados. Partiendo de la base que la función de los tribunales de justicia será siempre la de determinar si la pretensión se ajusta al ordenamiento jurídico más allá de los extremos en que se haya debatido por las partes, no es cuestionable entender que puede aplicar de oficio el Derecho para rechazar un reclamo de ilegalidad municipal. Ello puede generar un grado de indefensión procesal, pero que es natural en toda resolución judicial que resuelve una controversia con base a sus propios argumentos.

7. En cuanto a los hechos, no hay duda que la jurisdicción puede controlar si éstos se han establecido de manera correcta. Sin embargo, el impugnante no puede introducir en sede judicial hechos diferentes a los promovidos en sede administrativa y que modifiquen o alteren la causa de pedir. Por el contrario, nada impide que pueda introducir hechos nuevos de carácter secundarios, esto es, aquellos que no identifican la pretensión y que sirven como argumento para determinar un hecho principal. De igual forma, tratándose de los hechos nuevos o de nueva noticia, no incorporados en la etapa administrativa, estos pueden esgrimirse en sede judicial siempre y cuando reúnan las condiciones de la Ley $N^{\circ} 1.552$ (1902, art. 321 y 322).

\section{Agradecimientos}

Este trabajo fue realizado en el marco y con el financiamiento del Proyecto Fondecyt Regular N 1171244, titulado "Derecho Procesal Administrativo: acerca de las relaciones entre procedimiento administrativo y proceso jurisdiccional", del cual el autor de este trabajo es su investigador responsable.

\section{Referencias Bibliográficas}

Aguado i Cudolà, V. (2001). La prueba en el procedimiento administrativo sancionador. Justicia administrativa: revista de derecho administrativo, (Extra 1), 93114.

Aguas Araucanía S. A. con Comisión de Evaluación Ambiental IX Región, Rol N ${ }^{\circ}$ 10.235-2017 (Corte Suprema 15 de enero de 2018). Recuperado de https://bit.ly/2Cl5cWk 
Ángelo Solís Ruiz con Municipalidad de Pirque, Rol N 36676-2017 (Corte Suprema 25 de septiembre de 2017). Recuperado de https://bit.ly/3ebrDQR

Antileo con Municipalidad de Arica, Rol N³38-2017 (Corte Suprema 12 de octubre de 2017). Recuperado de https://bit.ly/3fdpm96

Barrero Rodríguez, C. (2006). La prueba en el procedimiento administrativo (3a ed.). Cizur Menor: Aranzadi.

Bellavista de Inversiones Limitada con Ilustre Municipalidad de Valparaíso, Rol $\mathrm{N}^{\circ}$ 101-2010 (Corte de Apelaciones de Valparaíso 5 de octubre de 2011).

Bellavista Oveja Tome SpA con Consejo de Monumentos Nacionales, Rol N $38655-$ 2017 (Corte Suprema 29 de diciembre de 2017). Recuperado de https://bit.ly/2OCnxqq

Bermúdez Soto, J. (2014). Derecho administrativo general (3a ed.). Santiago: Thomson Reuters.

Blanquer Criado, D. V. (2007). Curso de derecho administrativo: el fundamento y el control (Vol. 3). Valencia: Tirant lo Blanch.

Blanquer Criado, D. V. (2007b). La prueba y el control de los hechos por la jurisdicción contencioso-administrativa. Valencia: Tirant lo Blanch.

Bordalí Salamanca, A. (2005). Principios de una nueva justicia administrativa en Chile. En J. C. Ferrada Bórquez (Coord.), La justicia administrativa (pp. 341-381). Santiago: LexisNexis.

Bordalí Salamanca, A. y Hunter Ampuero, I. (2017). Contencioso administrativo ambiental. Santiago: Librotecnia.

Bordalí Salamanca, A. y Ferrada Bórquez, J. C. (2009). Estudios de justicia administrati$v a$ (2 $2^{\mathrm{a}}$ ed.). Santiago: Legalpublishing.

Carla Francisca Bon Fuenzalida con Municipalidad de Codegua, Rol № 97796-2016 (Corte Suprema 4 de mayo de 2016). Recuperado de https://bit.ly/2DoBohS

Carloni, E. (2011). Le verità amministrative. L' attività conoscitiva pubblica tra procedimento e proceso. Milán. Giuffrè Editore.

Castillejo Manzanares, R. (2006). Hechos nuevos o de nueva noticia en el proceso civil de la LEC. Valencia: Tirant lo Blanch.

Cencosud Administradora de Procesos S.A. con Inspección Provincial del Trabajo Puerto Montt, Rol N $100-2014$ (Corte de Apelaciones de Puerto Montt 29 de septiembre de 2014). Recuperado de https://bit.ly/32tzh6X 
Relaciones entre procedimiento administrativo y proceso jurisdiccional...

Colegio Almondale Valle con Superintendencia de Educación, Rol N 7037-2016, (Corte Suprema 22 de febrero de 2016). Recuperado de https://westlawchile.cl id: CL/JUR/1256/2016

Comanducci, P. (2001). Alcuni problema concettuali relativi alla applicazione del diritto. Diritto e questioni pubbliche, (10), 121-134. Recuperado de https://bit.ly/2CRYxc7

Comité Pro defensa del Patrimonio Histórico Cultural de Viña del Mar contra Res N¹135-2015 del Comité de Ministros (Servicio de Evaluación Ambiental. Tercero Coadyuvante: Inmobiliaria Punta Piqueros S.A.), Rol N 97792-2016 (Corte Suprema 6 de noviembre de 2017). Recuperado de https://bit.ly/30ldwDB

Compañía Minera Maricunga con Superintendencia del Medio Ambiente, Rol No R111-2016 (Segundo Tribunal Ambiental de Santiago, 31 de agosto de 2017). Recuperado de https://bit.ly/2WtUw4w

Comunidad Mapuche Sucesión Quiñimil Pirul y otros con Comisión Evaluación Ambiental VIII Región, Rol N 47629-2016 (Corte Suprema 29 de mayo de 2017). Recuperado de https://bit.ly/2ZJnVsg

Concesiones Recoleta S. A. con I. Municipalidad de Recoleta, Rol N 8110-2016 (Corte Suprema 14 de agosto de 2017). Recuperado de https://bit.ly/2O4ar54

Constitución Política de la República de Chile. Diario Oficial, Santiago, Chile, 22 de septiembre de 2005. Recuperado de http://bcn.cl/1uva9

Cordero Quinzacara, E. (2013). La nulidad de los actos administrativos en el Derecho Chileno. En J. C. Ferrada Bórquez (Coord.), La nulidad de los actos administrativos y sus causales (pp. 193-203). Santiago: Legalpublishing.

Cordero Vega, L. (2009). El control de la administración del Estado. Santiago: LegalPublishing

Cordero Vega, L. (2015). Lecciones de derecho administrativo. Santiago: Legalpublishing-Thomson Reuters.

Cordón Moreno, F. (2001). El proceso contencioso administrativo. Conforme a la Ley 29/1998, de 13 de julio, reguladora de la jurisdicción contencioso-administrativa (2a ed.). Navarra: Aranzadi Editorial.

Cordón Moreno, F. (2010). Cuestiones sobre la prueba en el proceso contencioso administrativo español. Revista de Derecho Universidad Piura, (11), 289- 310. Recuperado de https://bit.ly/3iniA2z

Corporación para el Desarrollo de la Región de los Ríos con Ministerio del Medio Ambiente, Rol N 83344-2016 (Corte Suprema 26 de julio de 2017). Recuperado de https://bit.ly/3gGEDzG 
Decreto con Fuerza Ley $N^{\circ} 1$. Fija el texto refundido, coordinado y sistematizado de la ley No 18.695, Orgánica Constitucional de Municipalidades. Diario Oficial de la República de Chile, Santiago, Chile, 26 de julio de 2006. Recuperado de http://bcn.cl/1 uuy1

Decreto con Fuerza Ley $N^{\circ} 1-19.653$. Fija texto refundido, coordinado y sistematizado de la ley № 18.575, Orgánica Constitucional de bases generales de la administración del Estado. Diario Oficial de la República de Chile, Santiago, Chile, 17 de noviembre de 200. Recuperado de http://bcn.cl/1uw4b

Decreto Ley 830. Código Tributario. Diario Oficial de la República de Chile, Santiago, Chile, 31 de diciembre de 1974. Recuperado de http://bcn.cl/1uw3h

Delgado/Contraloría General de La República, Rol N 35103-2017 (Corte Suprema 21 de septiembre de 2017). Recuperado de https://bit.ly/3gJ9USz

Ecomaule S. A con Superintendencia del Medio Ambiente, Rol N 3682-2017 (Corte Suprema 20 de diciembre de 2017). Recuperado de https://bit.ly/2Wr4F20

Emilio Fernando Dumont Bornandt contra Sr. Alcalde de la Municipalidad de Pitrufquén, Rol No 9677-2009 (Corte Suprema 29 de junio de 2011). Recuperado de https://bit.ly/2YXzih5

Empresa Nacional de Electricidad S.A. con Superintendencia del Medio Ambiente, Rol $N^{\circ}$ 5328-2016 (Corte Suprema 20 de septiembre de 2016). Recuperado de https://bit.ly/2ZMeWGW

Escribano Collado, P. (1993). Técnicas de control judicial de la actividad administrativa. En J. Barnes Cruzat, (Coord.). La justicia administrativa en el Derecho Comparado (pp. 351-372). Madrid: Civitas.

Escuela de Trastornos de la Comunicación Yamanqui, Yuly Calpe Zúñiga EIRL con Superintendencia de Educación, Rol N 7733-2015 (Corte Suprema 10 de septiembre de 2015). Recuperado de https://bit.ly/38F5uZZ

Espín Templado, E., Fernández Montalvo, R., Murillo de la Cueva, Pablo, P. L., Teso Gamella, M. P. y Xiol Ríos, J. A. (2016). Comentarios de la ley de la jurisdicción contencioso-administrativa. Valencia: Tirant Lo Blanch.

Ezquiaga Ganuzas, F. J. (2000). "Iura novit curia" y aplicación judicial del derecho. Valladolid: Lex Nova.

Falcon, G. (1993). La justicia administrativa. En J. Barnes Vásquez (Coord.). La justicia administrativa en el derecho comparado (pp. 207-251). Madrid: Civitas. 
Relaciones entre procedimiento administrativo y proceso jurisdiccional...

Fernández Rodríguez, T. R. (1969). Los vicios de orden público y la teoría de las nulidades en el derecho administrativo. Revista de Administración Pública, (58), 49- 126. Recuperado de https://bit.ly/3dNJL32

Fernández Torres, J. R. (1998). Jurisdicción administrativa revisora y tutela judicial efectiva. Madrid: Civitas.

Ferrada Bórquez, J. C. (2012). El sistema de justicia administrativa chileno: revisión de la legalidad de actos administrativos o protección de derechos y/o intereses. Revista de derecho (Valdivia), 25(1), 103-126. doi: 10.4067/S0718-09502012000100005

Ferrada Bórquez, J. C., y Sagredo Reyman, P. (2015). La tutela cautelar en la justicia administrativa chilena: fundamentos, regulación, limitaciones y desafíos. Revista de derecho (Valparaíso), (44), 337-367. doi: 10.4067/S0718-68512015000100010

Ferrer Beltrán, J. (2003). Derecho a la prueba y racionalidad de las decisiones judiciales. Jueces para la democracia, (47), 27-34. Recuperado de https://bit.ly/2BqdqIQ

Ferrer Beltrán, J. (2007). La valoración racional de la prueba. Madrid: Marcial Pons.

Gallardo Castillo, M. J. (2006). Los vicios de procedimiento y el principio de conservación del acto: doctrina jurisprudencial. Revista de administración pública. (171), 217247. Recuperado de https://bit.ly/2VI4rDh

Garberí Llobregat, J. y Buitrón Ramírez, G. (2004). La prueba civil. Valencia: Tirant lo Blanch.

García Pérez, M. (1998a). El objeto del proceso contencioso-administrativo. En su Jornadas de estudio sobre la jurisdicción contenciosa administrativa (pp. 47-80), Coruña: Universidad da Coruña. Recuperado de https://bit.ly/2BAWw3I

García Pérez, M. (1998b). La regla de la inalterabilidad de la pretensión en el proceso contencioso-administrativo. Anuario da facultade de dereito da Universidade da Coru$\tilde{n} a,(2), 299-317$. Recuperado de https://bit.ly/2YTK5sR

Gerardus Petrus van Eijck con Ilustre Municipalidad de Santiago, Rol № 6784-2007 (Corte Suprema 11 de mayo de 2009). Recuperado de https://bit.ly/2VMg1xa

Gómez Tomillo, M. y Sanz Rubiales, I. (2013). Derecho administrativo sancionador. parte general. Teoría general y práctica del derecho penal administrativo. Cizur Menor: Thomson Reuters-Aranzadi.

González Pérez, J. (1992). Manual de derecho procesal administrativo (2a ed.). Madrid: Civitas. 
Herman Pacheco Patricio Edgardo y otros con Ministerio del Medio Ambiente, Rol $\mathrm{N}^{\circ}$ 258-2017 (Corte Suprema 15 de enero de 2018). Recuperado de https://bit.ly/3hbkQZo

Hernández/Municipalidad de Fresia, Rol N 97928-2016 (Corte Suprema 4 de septiembre de 2017). Recuperado de https://bit.ly/38GAEjS

Huenchun Pilchulman Ana Rosa con Corp. Nac. y Des. Indígena (CONADI), Rol N 97731-2016, (Corte Suprema 14 de agosto de 2017). https://bit.ly/2BI9dtV

Huergo Lora, A. (2000). Las pretensiones de condena en el Contencioso-Administrativo. Cizur Menor: Aranzadi.

Hunter Ampuero, I. (2014). Reclamo de ilegalidad municipal en la jurisprudencia: caos interpretativo y criterios dudosos. Revista de derecho (Valdivia), 27(2), 191-215. doi: 10.4067/s0718-09502014000200009

Hunter Ampuero, I. (2015a). La aplicación judicial del derecho en el proceso civil. Doctrina, jurisprudencia y derecho comparado. Santiago: Thomson Reuters.

Hunter Ampuero, I. (2015b). La prueba en el procedimiento ante los tribunales ambientales. En J.C. Ferrada Bórquez, J. Bermúdez Soto y F. Pinilla Rodríguez (Coords.). La nueva justicia ambiental (pp. 225-251). Santiago: Thomson Reuters.

Inmobiliaria Casa de Italia S.A./ Consejo de Monumentos Nacionales, Rol N $33725-$ 2017 (Corte Suprema 17 de octubre de 2017). Recuperado de https://bit.ly/3iLQIKT

Inmobiliaria Collfran 2000 Ltda. contra llustre Municipalidad de Viña del Mar, Rol N ${ }^{\circ}$ 1508-2009 (Corte de Apelaciones de Valparaíso 23 de agosto de 2010). Recuperado de https://westlawchile.cl id: CL/JUR/5341/2010

Inmobiliaria Patagonia S.A., Inmobiliaria Parque Tres S.A. con Alcalde de la I. Municipalidad de Providencia, Rol № 73800-2016 (Corte Suprema 21 de agosto de 2017). Recuperado de https://bit.ly/2AKIJY8

Instituto San Pablo Misionero c Superintendencia de Educación, Rol N 18834-2015 (Corte Suprema 14 de diciembre de 2015). Recuperado de https://westlawchile.cl id: CL/JUR/7793/2015

Inversiones AF Limitada con Alcalde de la llustre Municipalidad de Macul Sergio Puyol Carreño, Rol N 938-2010 (Corte de Apelaciones de Santiago 13 de enero de 2011). Recuperado de https://vlex.cl id: 339896814

Inversiones CONFE Limitada con I. Municipalidad de Viña del Mar, Rol N 1804-2009 (Corte de Apelaciones de Valparaíso 10 de junio de 2010). 
Relaciones entre procedimiento administrativo y proceso jurisdiccional...

Inversiones Covadonga Ltda. contra Municipalidad de Vitacura, Rol No 12644-2004 (Corte de Apelaciones de Santiago 31 de mayo de 2005). Recuperado de https://westlawchile.cl id: CL/JUR/1776/2005

Inversiones e Inmobiliaria REVI Limitada con I. Municipalidad de Viña del Mar, Rol $\mathrm{N}^{\circ}$ 1421-2009 (Corte de Apelaciones de Valparaíso 28 de octubre de 2010). Recuperado de https://vlex.cl id: 339947230

Inversiones Juana de Arco Limitada con I. Municipalidad de Viña del Mar, Rol N ${ }^{\circ} 1411-$ 2009 (Corte de Apelaciones de Valparaíso 5 de mayo de 2010).

Inversiones Las Fresas LTDA. en contra de Municipalidad de lo Barnechea, Rol No 4204-2005 (Corte Suprema 20 de marzo de 2006). Recuperado de https://bit.ly/2NWhz3m

Inversiones Los Castaños Limitada con Alcalde de la I. Municipalidad de La Florida, Rol N 7346-2009 (Corte de Apelaciones de Santiago 27 de abril de 2010). Recuperado de https://vlex.cl id: 340011726

Inversiones Santa Julia S.A. con Ilustre Municipalidad de Valparaíso, Rol № 103-2010 (Corte de Apelaciones de Valparaíso, 24 de agosto de 2011).

Iturralde Sesma, V. (2004). Justificación judicial: validez material y razones. Analisis e diritto, (9), 119-151.

Jaime Romero Donoso contra Señor Alcalde de la I. Municipalidad de Punta Arenas, Emilio Bocazzi Campos, Rol No 9990-2014 (Corte Suprema 12 de junio de 2014). Recuperado de https://bit.ly/2O2Juio

Jequier Lehuede, E. (2013). Terminación unilateral del contrato de concesión municipal y reclamo de ilegalidad (Ley N 18.695, Orgánica Constitucional de Municipalidades). Análisis de jurisprudencia. Revista de derecho (Coquimbo), 20(1), 293-307. doi: 10.4067/S0718-97532013000100011

José Horacio Cayún Quiroz con Servicio de Evaluación Ambiental, Rol № 1008052016 (Corte Suprema 29 de diciembre de 2017). Recuperado de https://bit.ly/3fGYhv7

Lara Arroyo, J. L. y García-Huidobro Herrera, L. (2015). Aspectos fundamentales del reclamo de ilegalidad municipal. En G. Bocksang Hola y J. L. Lara Arroyo (Coords.). Administración territorial de Chile. Estudios sobre descentralización y desconcentración administrativas (pp. 165-208). Santiago: Thomson Reuters.

Ley de 27 de diciembre de 1956 reguladora de la Jurisdicción contenciosoadministrativa. Boletín Oficial del Estado, Madrid, España. Recuperado de https://bit.ly/3giEceu 
Ley 29/1998. Reguladora de la Jurisdicción Contencioso-administrativa. Boletín Oficial del Estado, Madrid, España, 14 de julio de 1998. Recuperado de https://bit.ly/2YWddzx

Ley $N^{\circ}$ 1.552. Código de procedimiento civil. Diario Oficial de la República de Chile, Santiago, Chile, 30 de agosto de 1902. Recuperado de http://bcn.cl/1uw3q

Ley $\mathrm{N}^{\circ}$ 19.300. Aprueba ley sobre bases generales del medio ambiente. Diario Oficial de la República de Chile, Santiago, Chile, 09 de marzo de 1994. Recuperado de http://bcn.cl/1 ux38

Ley $\mathrm{N}^{\circ} 19.880$. Establece bases de los procedimientos administrativos que rigen los actos de los órganos de la administración del Estado. Diario Oficial de la República de Chile, Santiago, Chile, 29 de mayo de 2003. Recuperado de http://bcn.cl/1uv5j

Ley N ${ }^{\circ}$ 20.600. Crea los Tribunales Ambientales. Diario Oficial de la República de Chile, Santiago, Chile, 28 de junio de 2012. Recuperado de http://bcn.cl/1 v6nd

Manzano Salcedo, Á. (2013). La prueba en el procedimiento administrativo. Barcelona: Bosch.

Marlene Carrasco Díaz con Gobernación Provincial del Tamarugal y Servicio de Gobierno Interior, Rol N 24987-2017 (Corte Suprema 3 de octubre de 2017). Recuperado de https://bit.ly/31ZzyOw

Medina Alcoz, L. (2005) La responsabilidad patrimonial por acto administrativo. Aproximación a los efectos resarcitorios de la ilegalidad, la morosidad y la deslealtad desde una revisión general del sistema. Madrid: Thomson Civitas.

Medina Alcoz, L. (2016a) Libertad y autoridad en el Derecho Administrativo. Derecho subjetivo e interés legítimo: una revisión. Madrid: Marcial Pons.

Medina Alcoz, L. (2016b). Los hechos en el derecho administrativo. Una aproximación. Revista española de derecho administrativo, (177), 103-158.

Méndez Ortíz, P. (2017). Tribunales Ambientales y contencioso administrativo. Santiago: Editorial jurídica de Chile.

Menéndez Rexach, Á. (2001). El control judicial de la inactividad de la administración. Anuario de la Facultad de Derecho de la Universidad Autónoma de Madrid, (5), 163-185. Recuperado de https://bit.ly/2ZwLqF1

Moderne, F. (1993). La justicia administrativa en Francia (II): proceso, técnicas de control, ejecución de sentencias. En J. Barnes Vázquez (Coord.). La justicia administrativa en el derecho comparado (pp. 319-325). Madrid: Civitas. 
Relaciones entre procedimiento administrativo y proceso jurisdiccional...

Montero Aroca, J. (2005). La prueba en el proceso civil (4a ed.). Navarra: ThomsonCivitas.

Moraga Klenner, C. (2010). La actividad formal de la administración del estado (Vol. 7, Tratado de derecho administrativo). Santiago, Chile: Abeledo Perrot.

Naviera Ultragas limitada contra Alcalde I. Municipalidad de Valparaíso, Rol N ${ }^{\circ} 276-$ 2011 (Corte Suprema 26 de noviembre de 2012). Recuperado de https://bit.ly/2Z5Gh80

Navieras Ultragas Limitada con Municipalidad de Valparaíso, Rol N²137-2009 (Corte de Apelaciones de Valparaíso 9 de diciembre de 2010). Recuperado de https://vlex.cl id: 339996238

Nieva Fenoll, J. (2006). La cosa juzgada. Barcelona: Atelier.

Pedro Pablo Díaz Cordero y otros contra Alcalde de la I. Municipalidad de Chillán, Rol $N^{\circ}$ 100-2009 (Corte Suprema 17 de diciembre de 2010). Recuperado de https://bit.ly/3gmrlT2

Pey Tumanoff Roxana contra Mario Fernández Baeza Vicepresidente de La República y Otro, Rol N 3598-2017 (Corte Suprema 19 de junio de 2017). Recuperado de https://bit.ly/3gDJGRi

Picó i Junoy, J. (1996). El derecho a la prueba en el proceso civil. Barcelona.

Picó i Junoy, J. (2006). La modificación de la demanda en el proceso civil. Valencia: Tirant lo Blanch.

Proceso contencioso-administrativo. Desviación procesal, $\mathrm{N}^{\circ} 1419$, ECLI: ES:TS:1987:9898 (Tribunal Supremo 2 de noviembre de 1987). Recuperado de https://bit.ly/3kfqpli

Rebollo Puig, M., Izquierdo Carrasco, M., Alarcón Sotomayor, L. y Bueno Armijo, A. (2010). Derecho Administrativo sancionador. Valladolid: Lex Nova.

Ricardo Escobar Pérez contra Sr. Alcalde Municipalidad de San Joaquín, Rol № 16582009 (Corte Suprema 20 de abril de 2011). Recuperado de https://bit.ly/2NSrw1V

Roberto Rodríguez Vergara en favor de Víctor Manuel Rodríguez Maban contra SERBANC, Rol No 1662-2017 (Corte Suprema 6 de abril de 2017). Recuperado de https://bit.ly/3iLapNy

Rodríguez de Santiago, J. (2016). Metodología del Derecho Administrativo. Reglas de racionalidad para la adopción y el control de la decisión administrativa. Madrid: Marcial Pons. 
Rodríguez/Superintendencia de Pensiones, Rol № 19033-2017 (Corte Suprema 4 de septiembre de 2017). Recuperado de https://bit.ly/2ZaJSRX

Romero Seguel, A. (1998). Notas sobre la legitimación en la jurisprudencia. Revista chilena de derecho, 25(3), 691-693. Recuperado de https://bit.ly/2YUIH99

Romero Seguel, A. (2014). La acción y la protección de los derechos. (2a ed., Vol. 1, Curso de Derecho Procesal Civil.). Santiago: Legalpublishing.

Romero Seguel, A. (2016). Los privilegios probatorios de la administración en la litigación pública. En J. Arancibia Mattar y A. Romero Seguel (Coord.). La prueba en la litigación pública (pp. 83 a 122). Santiago: Librotecnia,

Rosales Orellana Rosa Alicia con Superintendencia de Electricidad y Combustible, Rol $N^{\circ}$ 82245-2016 (Corte Suprema 13 de noviembre de 2017). Recuperado de https://bit.ly/3hgIVPH

Sánchez Medina con Municipalidad de Chillán, Rol N³68-2010 (Corte de Apelaciones de Chillán 31 de mayo de 2011). Recuperado de https://vlex.cl id: 339925634

Sociedad Agrícola El Tranque de Angostura Limitada con Superintendencia del Medio Ambiente, Rol N 18341-2017 (Corte Suprema 27 de diciembre de 2017). Recuperado de https://bit.ly/2CHTs6c

Sociedad Escuela Especial Diferencial Renacer Limitada con Superintendencia de Educación, Rol N 7358-2016 (Corte Suprema 29 de febrero de 2016). Recuperado de https://westlawchile.cl id: CL/JUR/1366/2016

Sociedad de Inversión Pizarro Limitada con Ilustre Municipalidad de Valparaíso, Rol $\mathrm{N}^{\circ}$ 1879-2009 (Corte de Apelaciones de Valparaíso 18 de agosto de 2010). Recuperado de https://westlawchile.cl id: CL/JUR/5203/2010

Sociedad Rentas Ardantza Limitada con Ilustre Municipalidad de Casablanca, Rol N ${ }^{\circ}$ 1751-2010 (Corte de Apelaciones de Valparaíso 30 de junio de 2011).

Tardío Pato, J. A. (2006). El principio constitucional de audiencia del interesado y el trámite del artículo 84 de la ley 20/1992. Revista de administración pública, (170), 93142. Recuperado de https://bit.ly/3gAALjJ

Taruffo, M. (2009). La prueba de los hechos (3a ed.) (J. Ferrer Beltrá, Trad.). Madrid: Trotta.

Tarullo, S. (2004). Il giusto processo amministrativo. Studio sull effettivita della tutela giurisdizionale nella prospettiva Europea. Milán: Giuffrè Editore.

Tolosa Tribiño, C. (2011). El valor del expediente administrativo. Revista jurídica CastiIla y León, (23), 205-230. Recuperado de https://bit.ly/2ZDuf4R 
Relaciones entre procedimiento administrativo y proceso jurisdiccional...

TRANSAP S.A. con Alcalde de la llustre Municipalidad de Requinoa, Rol № 6479-2005 (Corte Suprema 29 de junio de 2006). https://bit.ly/2VM34na

Valdivia Olivares, J. M., Contenido y efectos de las sentencias de los tribunales ambientales. En J. C. Ferrada Bórquez, J. Bermúdez Soto y F. Pinilla Rodríguez (Coords.). La nueva justicia ambiental (pp. 253- 276). Santiago: Thomson Reuters.

Valdivia Olivares, J. M. (2017) Reflexiones sobre las acciones en derecho administrativo. En A. Schopf Olea y Marín González, J. C. (Eds.). Lo público y lo privado en el derecho. Estudios en homenaje al profesor Enrique Barros Bourie (pp. 352-431). Santiago: Thomson Reuters.

Valenzuela/Jorquera (Dirección Obras I. Municipalidad Villa Alemana), Rol N $18154-$ 2017 (Corte Suprema 3 de agosto de 2017). Recuperado de https://bit.ly/3edxkOe

Vecinos Unidad Municipal de Providencia contra Municipalidad de Providencia, Rol $N^{\circ}$ 7127-2017 (Corte Suprema 3 de enero de 2017). Recuperado de https://bit.ly/3fHU5ew

Vilches/Municipalidad de Concón, Rol N 9237-2017, (Corte Suprema 3 de julio de 2017). Recuperado de https://bit.ly/2ZDHnrJ

Villablanca Muñoz Miguel Ángel con J. A. International S. A y Muñoz Luza Juan Andrés, Rol No 6065-2010 (Corte Suprema 2 de noviembre de 2011). Recuperado de https://bit.ly/3eDAXNx

\section{Para citar este artículo bajo Norma APA 6a ed. Hunter Ampuero, I. (2020). Relaciones entre procedimien- to administrativo y proceso jurisdiccional en el reclamo de ilegalidad municipal. Revista de Derecho (Coquimbo. En línea), 27, e4376, https://doi.org/10.22199/issn.0718- 9753-2020-0009}

Copyright del artículo: @2020 Iván Hunter.

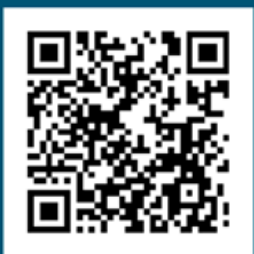

DOI

\section{(cc) BY}

Este es un artículo de acceso abierto, bajo licencia Creative Commons BY 4.0. 